\title{
Preferences and skills of Indian public sector teachers
}

\author{
Sonja Fagernäs ${ }^{1}$ and Panu Pelkonen ${ }^{1,2^{*}}$
}

\author{
* Correspondence: p.o.pelkonen@ \\ sussex.ac.uk. \\ ${ }^{1}$ Department of Economics, School \\ of Business, Management and \\ Economics, University of Sussex, \\ Jubilee Building, Brighton BN1 9SL, \\ UK \\ ${ }^{2}$ CEE, London School of Economics \\ and Political Science, London, \\ United Kingdom
}

\begin{abstract}
With a sample of 700 future public sector primary teachers in India, a Discrete Choice Experiment is used to measure job preferences, particularly regarding location. General skills are also tested. Urban origin teachers and women are more averse to remote locations than rural origin teachers and men respectively. Women would require a $26-73$ percent increase in salary for moving to a remote location. The results suggest that existing caste and gender quotas can be detrimental for hiring skilled teachers willing to work in remote locations. The most preferred location is home, which supports decentralised hiring, although this could compromise skills. Jel codes: 125, J41, J45

Keywords: Discrete choice experiment, Teacher recruitment, Job preferences, Hiring quotas, Skills, India
\end{abstract}

\section{Introduction}

Improvements in education and health are of primary importance in enabling people to overcome poverty. However, there are great difficulties in providing good quality public services in remote areas in developing countries. One key problem relates to attracting and retaining educated personnel in these difficult locations. Policy-makers have experimented with various approaches to motivate qualified key public service personnel to work in remote locations (see e.g. WHO, 2006).

This study examines the problem that is common to many developing countries, by analysing the recruitment of public sector teachers in India. The sample consists of approximately 700 teacher trainees studying at government training institutions in the state of Uttarakhand in 2010. In India, the recruitment decisions of teachers have traditionally been made at the state level and teachers have been recruited as civil servants on permanent contracts. However, the practice has been criticised for producing unmotivated teachers with little incentives, often absent as they choose to commute to their rural workplace from far (Sharma, 1999). In an important study, Kremer et al. 2005 find that in their sample of Indian primary schools, 25 percent of the teachers were absent during unannounced visits. School-level data for 2008 suggests that 94 percent of public sector primary schools in India are in rural locations. ${ }^{1}$ However, rural areas can lack amenities that urban-educated teachers are accustomed to. Multi-grade teaching, with one classroom and one teacher shared by all pupils, is also common.

The existing econometric studies on teacher absences and motivation in developing countries have focused mainly on incentive mechanisms to motivate teachers and

(c) 2012 Fagernäs and Pelkonen; licensee Springer. This is an Open Access article distributed under the terms of the Creative Commons Attribution License (http://creativecommons.org/licenses/by/2.0), which permits unrestricted use, distribution, and reproduction in any medium, provided the original work is properly cited. 
monitoring mechanisms to reduce absences (see e.g. Duflo et al. 2010; Glewwe et al. 2010; Kingdon and Teal, 2007; Muralidharan and Sundararaman, 2011; Banerjee et al. 2010). Another recent strand of literature studies the use of short-term contracts as an incentive mechanism. In particular, these studies have focused on the effects of the recruitment of local contract teachers (see e.g. Atherton and Kingdon, 2010; Bourdon et al. 2010; de Laat and Vegas, 2005; Duflo et al. 2012 and Muralidharan and Sundararaman, 2010).

This study approaches the question from a different perspective. Instead of the ex post incentives, or monitoring of teachers, it focuses on the job preferences and skills of teachers in order to draw inferences about the initial selection of teachers. We rely on a Discrete Choice Experiment (DCE) to measure the preferences of teachers at a training stage. This is a stated preference methodology that has been popular in the area of health and environmental economics for measuring preferences over various products or services. Its application to labour market questions is recent, and it has so far been used to study the job preferences of health workers (see e.g. Chomitz et al. 1998; Penn-Kekana et al. 2005; Hanson and Jack 2010; Mangham and Hanson 2008 and Kolstad 2011). As far as the authors are aware, ours is the first study that measures the job preferences of teachers in developing countries using such an experimental approach. In the context of developed countries, there is a literature analysing the preferences of teachers from observed data on actual postings and transfers (see e.g. Hanushek et al. 2004; Boyd et al. 2010 and Boyd et al. 2011).

In DCEs, the utility function of respondents is estimated from repeated choices of designed bundles of goods, or services that are presented to them. The DCE in this study focuses on the nature of the employment contract and pays particular attention to preferences over geographical location. The study focuses specifically on how the characteristics and selection criteria of the teacher trainees affect preferences. While some of the trainees have been competitively selected, gender balance and quotas for those with a low caste background also determine selection. Additionally, approximately half of the trainees were selected from a pool of current contract teachers (parateachers). ${ }^{2}$ Here, these trainees are examined to gain further insights on the preferences of teachers who are local to rural areas. The results also provide estimates of the monetary compensation needed to attract teachers to remote schools.

The DCE reveals substantial differences in job preferences, in particular with respect to preferred location. These differences are related to a range of observable characteristics of the trainees. Most prominently, it is found that gender and rural origin have a significant association with willingness to work in rural areas. There are also significant differences between the preferences of the competitively selected trainees and the former para-teachers. On average, the former strictly prefer all other locations over remote areas, whereas this is not the case for the former para-teachers. Among the competitively selected students, women are significantly more reluctant to work in remote areas than men. However, gender differences with respect to location are less pronounced among para-teachers. Caste has no effect on job preferences.

To our knowledge, our study is also the first to combine a DCE of public sector worker preferences with a documentation of the performance of the workers in a basic skills test, here consisting of knowledge of countries, English vocabulary, and Arithmetic. Our study finds substantial, and partly worrying heterogeneity in general skills. 
The joint analysis of preferences and skills raises concerns over the appropriateness of the current selection quotas. Women have lower general skills than men, lower caste trainees have lower skills than upper caste trainees and former para-teachers have lower skills than the competitively selected teachers.

In drawing policy conclusions from the analysis, it is assumed that preferences and tested skills are not irrelevant for the effectiveness of an individual as a teacher. The results indicate that the application of existing quotas, which are set nationally in India, is likely to lead, not only to teachers with on average lower willingness to work in rural areas, but also to a lower levels of skills. Our results also offer cautious support for a more decentralised hiring system. The most preferred location is the home location, particularly among women. Rural origin trainees are less averse to rural locations than urban origin teachers. Among competitively selected teachers, rural trainees are not less skilled than urban origin trainees. However, if in remote areas, decentralised hiring would mainly attract candidates who resemble the former para-teachers, suitable location preferences would come at the cost of low skills.

The article is organised as follows. Section 2 reviews the key background literature and Section 3 describes the background to primary education and teacher training in India and Uttarakhand. Section 4 discusses the data and reports the descriptive statistics. Section 5 presents the details of the Discrete Choice Experiment used in the study. Sections 6 and 7 report the results of the experiment and the skills test, and Section 8 discusses the policy implications more broadly.

\section{Background literature}

The study is related to several branches of literature on the recruitment of public sector workers in developing countries, of which the most relevant ones are discussed below. The focus is on studies on developing countries.

The study relies on a Discrete Choice Experiment (DCE) to measure job preferences. The methodology will be described in detail in Section 5. However, a few studies most relevant to ours are described in this section. The DCE is used to measure how teachers value different contract features. Traditional contingent valuation methods, that analyse individuals' willingness to pay for a certain product, or service, have been criticised, for instance by Diamond and Hausman 1994 as "deeply flawed", with many potential sources of inconsistency. In DCEs, respondents are presented repeatedly with goods, services, or contracts that represent bundles of characteristics. The utility function of respondents is estimated from the choices made. Since the valuations are indirectly inferred from choices and the individuals choose options that represent a bundle of characteristics, there may be less scope for strategic responses than in traditional contingent valuation designs. DCEs can also be considered better suited to address multidimensional trade-offs and more informative as each respondent bases decisions on multiple characteristics. A brief survey of the method, and how it has improved the elicitation of preferences, is provided for instance by Hanley et al. 2001

The application of DCEs to analyse human resource policy questions is recent, but expanding. Their use in this field has so far been limited to health workers. A recent surge of articles using DCEs for human resource questions in the area of Health Economics is reviewed by Guttman et al. 2009. DCEs have gained interest in this context 
given the absence of data sets on actual choices that public sector workers have made regarding their jobs in developing countries. They are particularly attractive when the variation in the range of key job characteristics studied is limited. In a recent review, Lagarde and Blaauw 2009 identify nine existing studies that assess how DCEs have contributed to the study of health worker preferences.

In the context of developing countries, the DCE studies by Chomitz et al. 1998, Penn-Kekana et al. 2005; Hanson and Jack 2010; Mangham and Hanson 2008 and Kolstad 2011 on the preferences of health workers could be mentioned. The studies have focused on the role of pecuniary versus non-pecuniary (working conditions, resources, training) characteristics of the contract, and less on the nature of the contract itself. Location choice has been a common component in these studies, given the dilemma of attracting workers to rural, or unattractive locations. Generally, wage equivalents of preferences over different job attributes have been estimated. Serneels et al. 2007 and Serneels et al. 2010 use a contingent valuation framework with a payment cards approach to elicit the monetary rewards associated with attracting health workers to rural locations in Ethiopia and Rwanda.

The studies generally show a preference for urban locations and that substantial salary increases would be required to attract workers to less urban locations. Some of the studies find that individuals who come from rural areas are generally more willing to return to work in such areas (e.g. Chomitz et al. 1998; Serneels et al. 2010). Serneels et al. 2007 and Kolstad 2011 also observe that individuals, who in an experiment were more willing to help the poor, were also more willing to work in rural areas. The results by Hanson and Jack 2010 and Kolstad 2011 suggest that women had a higher preference for urban locations than men.

In order to analyse how preferences and characteristics are associated with skills, the teacher trainees in our study were also asked to complete a simple skills test. There is still little systematic evidence on teachers' skills in India, or developing countries generally. In India, the SchoolTELLS survey revealed significant gaps, especially in the knowledge of Mathematics, among public sector primary school teachers in 2007-08 in Bihar and Uttar Pradesh (see Banerji and Kingdon, 2010). Our test measured general, or subject knowledge, and not teaching skills as such. However, general knowledge and subject skills can be expected to matter for the quality of teaching. A recent survey (Bhattacharjea et al. 2011) of 700 teachers in five Indian states found a correlation between a teachers' subject knowledge and pupil achievement. Evidence by Metzler and Woessman 2010 from Peruvian primary schools shows, that a one standard deviation increase in teacher test scores in subject knowledge raises student test scores by 10 percent of a standard deviation.

The selection of teachers into the training included quotas for women and lower castes, and the association of these factors with preferences and skills is studied explicitly. While our study cannot demonstrate the effects of these factors on pupil performance, it is worthwhile mentioning some key literature in this context. Typical arguments for female and caste quotas are to avoid gender discrimination in selection, but also that women can encounter female role models (see e.g. Beaman et al. 2012), or that students encounter less prejudice if taught by teachers who share their gender, or caste. Some studies in a developed country context have found that pupils perform better when taught by a teacher who shares their gender, or race (see e.g. Dee, 2005, 
2007). In the Indian context, an unpublished study by Rawal and Kingdon 2010 finds that students benefit from being taught by a teacher who shares their caste, or gender. However, a recent study for several countries questions the benefits of teacher-student gender matching (Cho, 2012). While some of the previous DCE studies on health worker preferences have found some gender differences in preferences, these results have not been discussed in the context of selection quotas, or skills.

\section{Primary education and teacher recruitment in India and Uttarakhand}

According to the 2009 Annual Status of Education Report, ${ }^{3}$ on average 64 percent of school children in rural India within classes 3-5 have elementary reading skills, but there is great state level variation. The figure in the state of Uttar Pradesh is 48 percent, whilst that in Himachal Pradesh is 82 percent and in Madhya Pradesh 88 percent. The state of Uttarakhand has been a somewhat above average performer, with 74 percent of pupils in classes 3-5 with elementary reading skills in the 2009 ASER survey. According to the DISE 2008-2009 data, the average government primary school in the state of Uttarakhand has 2.3 teachers and 11 grade 1 pupils.

In Uttarakhand, training for public sector primary school teachers is provided exclusively by public sector training institutes, the District Institutes for Educational Research and Training (DIETs). The State Council for Educational Research and Training (SCERT) oversees the DIETs. A new two-year programme, the Basic Teaching Certificate (BTC) was initiated in April 2010. The BTC training is required to be able to work as a regular teacher in a public sector primary school. There are a total of 13 DIETs in Uttarakhand, of which 3 are so called "mini-DIETs", given that they are located in districts with a smaller number of schools. (see Godiyal and Nautiyal 2008 for details).

In the 2011 Census, ${ }^{4}$ Uttarakhand is reported to have 10.1 million inhabitants, with a rural population of 69 percent. The state is relatively small geographically in comparison with many other Indian states, but a significant part of its territory consists of mountains. Travel times can be long even between short distances, and therefore remote locations pose a clear challenge for teacher recruitment.

A Universalisation of Elementary Education (Sarva Shiksha Abhiyan, SSA) scheme, in operation around India since 2001, has aimed to improve the educational opportunities of rural children. In order to alleviate a shortage of staff in rural areas, local contract teachers have been used to staff schools in remote locations. These teachers do not have formal teaching qualifications and are employed on a contract basis with significantly lower salaries than those of regular teachers. However, the national Right to Education Act $2010^{5}$ has restricted the use of untrained teachers, and the government of Uttarakhand decided to end the recruitment of para-teachers and offer BTC training for the existing para-teachers to enable them to become regular teachers.

In 2010, there were 200 students in each $\mathrm{DIET}^{6}$ on the new training programme. $\mathrm{Al}$ most all students in the district specific DIETs came from the same district. They will also be recruited as teachers in the same district. There was a two stream selection process of the students into the BTC programme. Half of the students (to be referred to as 'standard students') were selected on the basis of a composite entry score, which is a sum consisting of the entrance exam score and points based mainly on earlier educational qualifications. The entrance exam tested specific subject knowledge and 
teaching aptitude. All trainees were required to be educated to graduate level (a Bachelor level degree). In line with the principles of the Sarva Shiksha Abhiyan (SSA) programme, there was a 50 percent female quota. ${ }^{7}$ Further, to meet the nationally set reservations, there was a 37 percent quota for lower caste students. The other half of the students were former para-teachers, who were not selected on the basis of entry scores, but the number of years of teaching experience. The remaining para-teachers in the state, who did not fit into the BTC training programme, were to be trained on a distance learning Open University programme. Same caste and female quotas applied to the former para-teachers.

The starting salary of a regular teacher in Uttarakhand in 2010 was approximately Rs. 17-18.000 per month (\$340). A "cost of living" allowance, as well as a "hill area" allowance, are provided in some circumstances, and a "housing allowance" if appropriate government accommodation is unavailable. ${ }^{8}$ The starting salary is considerably higher than in some other states, although there have been recent increases elsewhere as well following the recommendations of the Sixth Pay Commission (see e.g. Kingdon, 2010).

\section{Data and descriptive statistics}

The survey was carried out in DIETs in seven out of 13 districts of Uttarakhand. The state of Uttarakhand was chosen for its manageable size, but also the introduction of a new teacher-training programme, including both former para-teachers and 'standard' students. The survey was conducted in May 2010, right after the students (both standard students and former para-teachers) had entered the BTC programme.

Since the students had only recently entered the training programme, it can be assumed that the programme itself had not significantly shaped their skills or preferences. The study captures all teachers at an entry point to their careers as regular public sector teachers. One distinguishing factor between the two groups of students is that para-teachers have more teaching experience, although many of the standard students have some experience from private sector schools.

The main criterion for the choice of districts was the diversity in geography. It was considered appropriate to include two geographically "flat" districts (Haridwar and Udham Singh Nagar) where conditions resemble those of other Northern Indian States. In addition, the district including the state capital was included (Dehradun). Out of the remaining four districts included, two can be considered remote mountain districts (Chamoli and Rudraprayag) and two less remote, mountainous districts (Almora and Nainital). More details of the data collection process are presented in Appendix 1.

The questionnaire administered to the participants consisted of three parts. The first one focused on the general background of the students and their perceptions of the recruitment and work of teachers. This was followed by the discrete choice experiment and finally a timed, voluntary general skills test. The questions in the survey and job characteristics incorporated in the DCE were decided after discussions with a range of Indian education officials and academics, including officials in the state of Uttarakhand. The design was also influenced by findings in existing literature referred to above. A vast majority of the students had at least some teaching experience, and thus the presented choices should not be alien to them. The questionnaire as well as verbal instructions were given in both English and Hindi (the main language in the state). This 
section reports summary statistics. The replies to the DCE are analysed in Section 6, and skills in Section 7.

A total of 707 students participated in the survey of which 40 percent said they entered the BTC programme as para-teachers. Table 1 summarises the data for the core characteristics of the teacher trainees in the sample. The first column summarises data for all trainees on aggregate. The average age is 30 years and 70 percent had a Masters (MSc) degree. Everyone in the sample was educated to degree level (BSc), so this variable is excluded. Around 40 percent belong to a lower caste, and 75 percent are of a rural origin. Table 1 also shows the averages for men and women, separately for parateachers and the standard students.

There are larger differences between the para-teachers and the standard students. Para-teachers are somewhat older, a lower share has a Master's degree, almost all are of a rural origin, and a significantly higher share is married and has children. Parateachers naturally have significantly higher years of teaching experience, whereas a much larger share of the standard students have taught in private schools. Many of these characteristics will be controlled for in the regression analysis to understand whether para-teacher status as such affects preferences.

\section{Discrete choice experiment and the estimation of preferences}

As discussed above, the existing studies using DCEs to study the preferences of public sector workers have focused on health workers. The focus has tended to be on monetary versus non-monetary rewards, as well as rural versus non-rural location. In our study, the DCE focuses on the nature of the contract and pays particular attention to preferences over location by including four location categories.

In the experiment, all students were presented with pairs of contracts from which they had to select the one they prefer. These represented hypothetical contracts with

Table 1 Summary statistics

\begin{tabular}{|c|c|c|c|c|c|c|c|c|c|c|}
\hline & \multicolumn{2}{|c|}{ All } & \multirow{2}{*}{\multicolumn{2}{|c|}{$\begin{array}{c}\text { Standard } \\
\text { Male }\end{array}$}} & \multirow{2}{*}{\multicolumn{2}{|c|}{$\begin{array}{c}\text { Standard } \\
\text { Female }\end{array}$}} & \multirow{2}{*}{\multicolumn{2}{|c|}{$\begin{array}{l}\text { Para } \\
\text { Male }\end{array}$}} & \multirow{2}{*}{\multicolumn{2}{|c|}{$\begin{array}{c}\text { Para } \\
\text { Female }\end{array}$}} \\
\hline & \multirow[b]{2}{*}{ Obs } & \multirow[b]{2}{*}{ Mean } & & & & & & & & \\
\hline & & & $\overline{\text { Obs }}$ & $\overline{\text { Mean }}$ & Obs & $\overline{\text { Mean }}$ & Obs & $\overline{\text { Mean }}$ & Obs & Mean \\
\hline Female & 703 & .506 & 207 & 0 & 218 & 1 & 139 & 0 & 138 & 1 \\
\hline Para-teacher & 704 & .395 & 207 & 0 & 218 & 0 & 139 & 1 & 138 & 1 \\
\hline Age & 665 & 30.0 & 202 & 28.9 & 211 & 28.4 & 127 & 33.1 & 123 & 31.4 \\
\hline SC/ST/OBC & 701 & .417 & 206 & .422 & 218 & .431 & 138 & .493 & 137 & .314 \\
\hline MSc Degree & 700 & 699 & 207 & .739 & 216 & .852 & 138 & .551 & 137 & .547 \\
\hline Rural & 692 & .750 & 206 & .718 & 215 & .498 & 137 & .993 & 133 & .955 \\
\hline Married & 701 & .635 & 207 & .362 & 217 & .571 & 139 & .885 & 136 & .897 \\
\hline Any children & 703 & .541 & 207 & .266 & 218 & .422 & 139 & .820 & 137 & .861 \\
\hline Number of children & 703 & .999 & 207 & .401 & 218 & .628 & 139 & 1.784 & 137 & 1.686 \\
\hline Any experience & 691 & .754 & 204 & .554 & 208 & .625 & 139 & 1 & 137 & 1 \\
\hline Years of experience & 599 & 4.88 & 170 & 2.50 & 165 & 2.08 & 133 & 8.36 & 128 & 8.02 \\
\hline Taught at private school & 683 & .395 & 206 & .495 & 208 & .601 & 139 & .137 & 127 & .173 \\
\hline Salary at private school & 269 & 3837 & 100 & 4296 & 127 & 4067 & 18 & 1228 & 22 & 2711 \\
\hline
\end{tabular}


characteristics that were deemed to be generally important and relevant for a teacher's job. To elicit a sufficient amount of information regarding preferences over the characteristics (attributes) of the contracts, the selection was repeated multiple times with different levels of the contract attributes. In our case, the number of contract pairs was 12 (see Appendix 3 for a justification). The contract attributes and their levels are presented in Table 2 below. A sample page of the survey is presented in Appendix 3. This section of the questionnaire was not timed; the students were given the amount of time they required to complete the section. All students received the same contract pairs to choose from.

The students were explained that this was an independent study and that individual responses would remain confidential and would not be revealed to education officials, or members of staff at the school. The aim was to minimise the tendency to provide "correct" answers as opposed to true preferences. As mentioned earlier, the multidimensionality of the DCE framework also mitigates such strategic responses.

There are limitations to how many attributes can be chosen to be able to estimate the DCE (see Appendix 3). The incorporation of pay was considered necessary, as it was likely to be of fundamental importance and necessary to calculate the monetary valuation of other attributes. The attributes and their levels were chosen to be relevant and approximately realistic for the state of Uttarakhand and India to a large extent.

Given the focus on location, it was considered appropriate to include more than two location categories. For instance, from the perspective of recruitment policy, it would be useful to know to what extent students prefer to work in their home village or town. The interpretation of the location should be straightforward for the teacher trainees, but it is important to recognise that respondents may associate locations with features not explicitly controlled for in the DCE. For example, the 'Remote village' option will reflect distance, but is also likely to be associated with factors such as lack of services, electricity, or possibly lack of school resources.

An attribute on the contract type was also considered important, given the concerns with permanent contracts and increased tendency to recruit teachers on a contract basis in India. The existing studies on the job preferences of public sector workers referred to above have tended to ignore this dimension. The attribute levels for the contract types incorporate both geographic rotation ${ }^{9}$ and permanence of the contract. Three types of contracts are included: fixed term, which is renewable every 7 years, permanent with rotation/transfer of location every 7 years, and permanent with the possibility to transfer every 7 years. The duration of a period until a change was kept

Table 2 DCE: Contract attributes, and their levels

\begin{tabular}{|c|c|c|c|c|}
\hline Pay & Location & Contract & Transfers & $\begin{array}{l}\text { Staff and } \\
\text { pupils }\end{array}$ \\
\hline $\begin{array}{l}\text { Rs. } 13000 \text { per } \\
\text { month }\end{array}$ & Remote village & $\begin{array}{l}\text { Fixed term contract, renewable } \\
\text { every } 7 \text { years. }\end{array}$ & $\begin{array}{l}\text { Depend on connections } \\
\text { and influence }\end{array}$ & $\begin{array}{l}2 \text { teachers, } 75 \\
\text { pupils }\end{array}$ \\
\hline $\begin{array}{l}\text { Rs. } 17000 \text { per } \\
\text { month }\end{array}$ & $\begin{array}{l}\text { Village / Small } \\
\text { town }\end{array}$ & $\begin{array}{l}\text { Permanent, must transfer every } \\
7 \text { years. }\end{array}$ & Depend on merit & $\begin{array}{l}2 \text { teachers, } 14 \\
\text { pupils }\end{array}$ \\
\hline \multirow[t]{2}{*}{$\begin{array}{l}\text { Rs. } 21000 \text { per } \\
\text { month }\end{array}$} & $\begin{array}{l}\text { Your home } \\
\text { village / town }\end{array}$ & $\begin{array}{l}\text { Permanent, possibility to } \\
\text { transfer after } 7 \text { years. }\end{array}$ & & \\
\hline & $\begin{array}{l}\text { District capital } \\
\text { area }\end{array}$ & & & \\
\hline
\end{tabular}

Notes: 1 USD 50 Rupees. The 2010 starting salary in Uttarakhand was 17-18.000 Rs per month (\$340). 
constant to be able to compare the contract types with each other. Given that the current trainees were expected to be posted to a rural location for 10 years initially, 7 years is not an unrealistic value. Offering teachers permanent contracts with regular rotation of location is a possible option for guaranteeing that remote schools are staffed.

Transfers are believed to be affected by corruption, with political connections, or ability to pay playing a role. ${ }^{10}$ When considering whether to prefer a permanent contract with the option to change, or a permanent contract with obligatory transfers, we might also expect teachers to take into consideration on what basis the decisions on transfers are made. Formulating a DCE question on the topic was challenging, but we wanted to understand how teachers value merit-based transfers as opposed to ones based on 'connections and influence'.

The final attribute, the teacher-pupil ratio, is included as a general indicator of the demand level of the job. Based on DISE 2008 data, 10 percent of two-teacher public sector schools in Uttarakhand have 75, or more students, and 10 percent have 14 or less students.

A discrete choice regression model is used to analyse the relative importance of different contract attributes for preferences and especially, whether location options significantly affect choices. As explained below, the analysis allows one to assess on what terms teachers would be willing to trade one job characteristic for another.

\section{The model}

Following the much used random utility framework (McFadden, 1974), we assume that utility from a job contract can be characterised by a function

$$
U_{c i}=a+\sum_{k=1}^{K} \beta_{k} X_{c k}+\sum_{m=1}^{M} \gamma_{m} Z_{m i}+\sum_{k=1}^{K} \sum_{m=1}^{M} \delta_{k m} X_{c k} Z_{m i}+u_{c i}
$$

where contract $c=\{A, B\}$ and $i=1 \ldots \mathrm{N}$ refers to individuals. $X$ is a vector of $K$ attribute levels, and $Z$ is a vector of $M$ personal characteristics. The parameter $\beta_{k}$ refers to the utility associated with a contract attribute $k$ and the parameter $\delta_{k m}$ measures how this utility varies by a specific characteristic of the individual. The term $u_{c i}$ is random and represents unobservable influences on individual choice.

The framework assumes that the individual chooses the contract option, which generates more utility. Now, the utility gain from contract $B$ over contract $A$ for individual $i$, is:

$$
U_{B i}-U_{A i}=\sum_{k=1}^{K} \beta_{k}\left(X_{B k}-X_{A k}\right)+\sum_{k=1}^{K} \sum_{m=1}^{M} \delta_{k m}\left(X_{B k}-X_{A k}\right) Z_{m i}+\left(u_{B i}-u_{A i}\right)
$$

The random component $u_{c i}$ may be hypothesised to consist of three additive components: an individual specific component $v_{i}$, a contract specific component $e_{c}$ and a true iid random term. Of these, the individual specific term cancels out. The contract specific component can be assumed to be zero, unless the respondents have a consistent tendency to be more or less likely to respond to contract $A$ instead of $B$, for instance due to their placement on the paper (this will be tested below as a robustness check). Suppose the individual chooses contract $B$ if $U_{B i}-U_{A i}>0$. This takes place with the probability 


$$
\begin{gathered}
P\left[U_{B i}-U_{A i}>0\right]=P\left[\sum_{k=1}^{K} \beta_{k}\left(X_{B k}-X_{A k}\right)+\sum_{k=1}^{K} \sum_{m=1}^{M} \delta_{k m}\left(X_{B k}-X_{A k}\right) Z_{m i}+\left(u_{B i}-u_{A i}\right)>0\right] \\
=P\left[\left(u_{A i}-u_{B i}\right)<\sum_{k=1}^{K} \beta_{k}\left(X_{B k}-X_{A k}\right)+\sum_{k=1}^{K} \sum_{m=1}^{M} \delta_{k m}\left(X_{B k}-X_{A k}\right) Z_{m i}\right]
\end{gathered}
$$

Assuming a distribution for $\left(u_{A i}-u_{B i}\right)$, for instance a logistic distribution, the probability in (3) can be expressed in terms of a logistic cumulative distribution and modelled accordingly with Logit:

$$
P\left[U_{B i}-U_{A i}>0\right]=F\left[\sum_{k=1}^{K} \beta_{k}\left(X_{B k}-X_{A k}\right)+\sum_{k=1}^{K} \sum_{m=1}^{M} \delta_{k m}\left(X_{B k}-X_{A k}\right) Z_{m i}\right]
$$

where $F(\mathrm{x})=\exp (\mathrm{x}) /(1+\exp (\mathrm{x}))$. This paper estimates Equation 4 with a logit model in all cases, but the results would be virtually the same if one would use a probit specification instead. The levels of the contract attributes are treated as separate dummy variables in the regression analysis, except for pay which enters as a single variable. The estimated models are based on differenced contract attributes as specified in Equations (2)-(3). Since the explanatory variables represent the differences between the attribute levels of two contracts, it is unnecessary to include individual effects (such as random effects). Appendix 3 describes the design of the DCE in more detail.

One downside of a discrete choice experiment is that the interview setting does not constitute a real, but a stated choice. Some studies have been carried out to assess the reliability of stated preference in predicting actual behaviour, and they tend to show good correspondence (e.g. Adamowicz et al. 1994). In the context of health worker preferences, Chomitz et al. 1998 find a "strong qualitative consistency" between stated and revealed preference.

\section{Results}

Given the significantly different selection process of the standard students and the para-teachers, separate models are estimated for the two. The focus is on the standard students, but the results for para-teachers are discussed in the context of preferences of teachers from remote areas. The main aim of the study is to understand how characteristics and selection criteria affect preferences, with a particular focus on rural versus urban origin, gender and caste. All contract attribute variables, except pay, are dummy variables, which makes the coefficients directly comparable with each other. A larger value for a specific attribute implies that this contract feature attracts the respondents towards choosing the contract. The effects of individual characteristics on the preference parameters are measured through interaction terms between the contract attributes and specific characteristics.

The interpretation of DCEs generally focuses on the trade-offs between different contract attributes. This can be done by comparing directly the estimated coefficients, but we will also provide marginal effects for core effects of interest in the text. 
Table 3 Logit estimates of the DCE model, standard students

\begin{tabular}{|c|c|c|c|c|c|c|c|c|}
\hline Contract attributes & & [1] & & 2] & & 3] & & 4] \\
\hline Pay (1000 Rs.) & .132 & {$[.011]^{* *}$} & .133 & {$[.010]^{* *}$} & .121 & {$[.013]^{* *}$} & .139 & {$[.026]^{* *}$} \\
\hline Location: Village/Small town & .507 & {$[.095]^{* *}$} & .576 & {$[.088]^{* *}$} & .779 & {$[.105]^{* *}$} & .880 & {$[.220]^{* *}$} \\
\hline Location: Home village / town & .658 & {$[.095]^{* *}$} & 1.022 & {$[.092]^{* *}$} & 1.225 & {$[.115]^{* *}$} & 1.104 & {$[.230]^{* *}$} \\
\hline Location: District Capital area & .368 & {$[.096]^{* *}$} & .636 & {$[.091]^{* *}$} & 1.006 & {$[.110]^{* *}$} & .749 & {$[.225]^{* *}$} \\
\hline Contract: Permanent with rotation & .673 & {$[.068]^{* *}$} & .577 & {$[.063]^{* *}$} & .681 & {$[.076]^{* *}$} & .700 & {$[.157]^{* *}$} \\
\hline Contract: Permanent & .783 & {$[.100]^{* *}$} & .723 & {$[.094]^{* *}$} & .770 & {$[.117]^{* *}$} & .833 & {$[.238]^{* *}$} \\
\hline Transfers: Based on merit & .940 & {$[.074]^{* *}$} & 1.035 & {$[.071]^{* *}$} & 1.048 & {$[.088]^{* *}$} & .891 & {$[.176]^{* *}$} \\
\hline Small class size & -.128 & {$[.060]^{*}$} & -.043 & {$[.056]$} & -.127 & {$[.067]$} & -.173 & {$[.137]$} \\
\hline Female x Pay (1000 Rs.) & -.007 & {$[.016]$} & & & & & -.003 & {$[.017]$} \\
\hline Female $\times$ Village/Small town & .188 & {$[.134]$} & & & & & .170 & {$[.144]$} \\
\hline Female $x$ Home village / town & .704 & {$[.141]^{* *}$} & & & & & .701 & {$[.151]^{* *}$} \\
\hline Female $\times$ District Capital area & .563 & {$[.138]^{* *}$} & & & & & .469 & {$[.149]^{* *}$} \\
\hline Female $\times$ Permanent with rotation & -.184 & {$[.096]$} & & & & & -.224 & {$[.103]^{*}$} \\
\hline Female $\times$ Permanent & -.067 & {$[.144]$} & & & & & -.065 & {$[.155]$} \\
\hline Female $\times$ Based on merit & .223 & {$[.108]^{*}$} & & & & & .267 & {$[.116]^{*}$} \\
\hline Female $\times$ Small class size & .127 & {$[.084]$} & & & & & .159 & {$[.091]$} \\
\hline Caste x Pay (1000 Rs.) & & & -.011 & {$[.016]$} & & & -.013 & {$[.016]$} \\
\hline Caste $\times$ Village/Small town & & & .026 & {$[.135]$} & & & .043 & [.139] \\
\hline Caste $\times$ Home village / town & & & -.069 & {$[.140]$} & & & -.073 & [.144] \\
\hline Caste $\times$ District Capital area & & & .002 & {$[.139]$} & & & .067 & {$[.143]$} \\
\hline Caste $\times$ Permanent with rotation & & & -.019 & {$[.097]$} & & & .039 & {$[.099]$} \\
\hline Caste $\times$ Permanent & & & .039 & {$[.145]$} & & & .050 & {$[.149]$} \\
\hline Caste $\times$ Based on merit & & & .004 & {$[.108]$} & & & .014 & {$[.112]$} \\
\hline Caste $\times$ Small class size & & & -.059 & {$[.085]$} & & & -.080 & {$[.087]$} \\
\hline Rural x Pay (1000 Rs.) & & & & & .012 & {$[.016]$} & .011 & {$[.017]$} \\
\hline Rural $\times$ Village/Small town & & & & & -.319 & {$[.136]^{*}$} & -.290 & {$[.143]^{*}$} \\
\hline Rural x Home village / town & & & & & -.375 & {$[.144]^{* *}$} & -.221 & {$[.151]$} \\
\hline Rural x District Capital area & & & & & -.611 & {$[.141]^{* *}$} & -.516 & {$[.148]^{* *}$} \\
\hline Rural x Permanent with rotation & & & & & -.181 & {$[.098]$} & -.226 & {$[.103]^{*}$} \\
\hline Rural x Permanent & & & & & -.04 & [.149] & -.054 & {$[.155]$} \\
\hline Rural x Based on merit & & & & & -.008 & {$[.112]$} & .061 & {$[.116]$} \\
\hline Rural x Small class size & & & & & .099 & {$[.086]$} & .139 & {$[.090]$} \\
\hline Additional Controls & & & & & & & & Yes \\
\hline
\end{tabular}

\subsection{Preferences of 'Standard students'}

Table 3 presents the results for a set of models for the sample of standard students. The coefficients in the table refer to the estimated $\beta$ :s and $\delta: \mathrm{s}$ of Models [1]-[4]. They measure whether the attribute levels make respondents more likely to choose contract B. Reference groups (for dummy variables) are excluded from the models. For location, the reference group is "Remote village". For the contracts, the reference group is "Fixed term contract, renewable every 7 years". For transfers, the base category is "Transfers 
based on connections and influence", and for pupils and staff, the excluded category is " 2 teachers, 75 pupils" ("Large class size"). Thus, the estimated parameters refer to preferences compared to these categories; in other words a significant positive coefficient would measure the extent to which the option is likely to be preferred over the excluded category. Since the model includes pay as an independent variable, monetary equivalents for the preference parameters can be calculated in order to facilitate interpretation.

The first regression model in Table 3 focuses on the preferences of male versus female students without controlling for other characteristics. The set of parameters for the contract attributes presented at the top of the table in model [1] can be interpreted as the preference parameters for men. The interaction terms indicate how the preference parameters of women differ from those of men. The preference parameters for women can be calculated by summing the two sets of estimated coefficients.

To begin with the estimates for men, all parameters are statistically significant and with the possible exception of class size, have the expected sign. Male trainees value pay and have a clear preference for all other locations than the remote location. The home location is the most preferred location, although men are statistically indifferent between home and the village/small town category $\left(\mathrm{H}_{0}: .658-.507=0, \mathrm{p}=.23\right)$. The marginal effects of different locations for men are as follows: 'Small town': .122, 'Home': .158 and 'Capital': .089. These indicate that men are for instance 15.8 percentage points more likely to choose a contract with their home location than one with a remote village. Men also prefer permanent contracts over a fixed contract. However, they are indifferent between whether the permanent contract involves compulsory rotation, or not $\left(\mathrm{H}_{0}: .783-.673=0, \mathrm{p}=.36\right)$. The marginal effects for contracts are .162 for a permanent contract with rotation and .189 for one without rotation. Male trainees have a strong preference for merit based transfers, the marginal effect for merit-based transfers being .226. The sign for small class size is negative, suggesting that the average male trainee actually slightly prefers a larger school with 75 pupils to the alternative with 14 pupils and two teachers. Overall, the results indicate that merit based transfers, a permanent contract, and home location are the most desired job characteristics for male trainees.

Turning to the female interaction terms in the first column, we find that women are more reluctant than men to work in a remote village. The interaction coefficients for all other locations are positive, and for the home location and the district capital, they are significantly and quite substantially larger than for men. The most preferred location for women is the home village/town. Overall, it can be concluded that women are significantly averse to remote locations. Secondly, in comparison with men, women appear to prefer permanent contracts without rotation more than permanent contracts with rotation, although we can reject the null hypothesis that women are indifferent between both types of permanent contracts, only at the 10 percent level $\left(\mathrm{H}_{0}:[.783-.067]-[.763-.184]=0, \mathrm{p}=.067\right)$. This result is sensible if women are assumed to have more responsibility over raising the family. Finally, women are relatively more appreciative of smaller class sizes than men, and overall, indifferent regarding class size $\left(\mathrm{H}_{0}:-.128+.127=0, \mathrm{p}=.98\right)$. Women also appreciate merit based transfers more than men. The marginal effects ${ }^{11}$ suggest that the differences in location preferences by gender can have a large practical significance. For the home location, the marginal effects for men and women are .158 and .329 respectively, suggesting 
that when given a choice, women are twice more likely to opt for home location. The same applies for the district capital, for which the marginal effects are .089 and .225 for men and women, respectively.

The model in column [2] focuses on the significance of caste for preferences, without controlling for other characteristics. As can be seen from the interaction terms in column [2], there appear to be no differences in preferences to any meaningful extent. A joint F-test of the caste interaction parameters does not reject the null hypothesis that they are jointly zero $(\mathrm{p}=.93)$.

The third column of Table 3 focuses on the relevance of self-reported urban/rural origin for preferences, without controlling for other characteristics. The interaction terms show that trainees from a rural area are less averse to working in remote locations. All non-remote locations are valued less by the rural than the urban trainees, and these differences are statistically significant. For example, the overall valuation of the district capital over a remote village for rural trainees is still positive, but clearly smaller $(1.006-.611=.395)$. Like women, the rural origin teachers appear to dislike contracts with rotation somewhat more than urban trainees $\left(\mathrm{H}_{0}:[.770-.040]-[.681\right.$ $.181]=0, \mathrm{p}=.037)$. In this case the result is statistically significant, although the intuition behind it is less clear. Urban trainees on the other hand, are indifferent with respect to rotation $\left(\mathrm{H}_{0}: .770-.681=0, \mathrm{p}=.53\right)$. There is a noteworthy difference between urban and rural trainees in terms of the marginal effects for the district capital dummy. For urban trainees, it is .241 and for rural, .096.

It should be emphasised that the estimates in columns 1 to 3 in Table 3 provide us only with unconditional estimates of the preferences of different groups, since they do not control for other characteristics. As such, the results may partially reflect the omission of confounding variables. The final column presents results of a model, which includes interaction terms for all the variables in the earlier columns as well as interaction terms with a few other control variables, namely, dummy variables for having children, teaching experience ${ }^{12}$ and a Master's degree. In principle, other interaction terms could have been included, but their relevance was questionable, in particular since there is a risk of significant multicollinearity with an increasing number of interaction terms. For instance, controls for age and marital status were not highly relevant after teaching experience and the dummy for children were included.

The results of the model with the full set of interactions are presented in the last column of Table 3. Only the coefficients of main interest are reported. Some of the interaction terms with other characteristics are significant, but many are not. Even with a full set of controls, gender remains a strong determinant of preferences. The conclusions from column 1 still hold, as the preference parameters for women remain nearly unchanged. Even with the control variables, caste is not associated with job preferences. On the other hand, rural origin still remains a statistically significant determinant of preferences, and it can still be concluded that teacher trainees of a rural origin are less averse to working in the most remote villages, than those of an urban origin.

Overall, the key findings of the models with a full set of interactions are that being female and of a rural origin are significant determinants of location preferences. Teachers from rural areas have a significantly weaker preference for both the district capital, and the village/small town category than teachers of an urban origin, when compared with the remote village option. Irrespective of the origin of the teacher, the most preferred 
location is the home location. Since the location of 'home' differs by respondent, urban origin trainees would prefer most their urban, home location, and rural origin trainees would prefer most their own, rural location. Women have a much stronger preference for their home location as well as for the district capital than men. In terms of preferences, the results so far would speak in favour of a more localised hiring strategy.

The results regarding contract type show that all examined groups prefer permanent contracts over fixed term contracts. On average, the trainees also prefer a permanent contract without compulsory rotation to one with rotation, but this difference is not large, and men and urban origin trainees appear to be indifferent regarding rotation.

To provide a more specific interpretation of the results in the last column of Table 3, Table 4 displays implied monetary equivalents of different locations for different individual characteristics. Standard errors are not shown in the table, but each figure is tested against the null hypothesis of zero. These computations rely on some assumptions. Since the utility function is assumed to be linear, the estimates assume perfect substitutability between contract attributes. While this is a simplification, it allows for convenient comparisons of contract features. For example, for urban origin men, an additional 1000 rupees $(\$ 20)$ per month would increase latent utility on average by .139 , and being located in the district capital instead of a remote village would increase it by .749 in relation to the remote area. These figures suggest that $1000 \times(.749 / .139)=$ 5388 rupees $(\$ 108)$ per month would be the amount that would make an urban origin male equally content with a remote village than with a district capital, assuming that all other job features are similar. However, rural origin men would not have to be compensated for a move from the district capital to a remote village as they are statistically indifferent between the two options.

The estimated compensating differentials for taking up a post in a remote village are very substantial given that a government teacher in Uttarakhand state had a starting salary of about $17-18.000$ Rs. per month (\$340) in 2010. Women are especially averse to moving away from their home village, particularly to a remote village, and would have to be compensated more than men to make them indifferent between the remote village and other locations. The estimates on monetary compensation indicate that if there were to be an extra compensation of 4000 rupees (\$80) per month, for taking up a post in a remote village, mainly men from rural areas would be likely to respond voluntarily to such an incentive. Irrespective of gender or rural origin, moving a teacher from their home location to a remote village would be the most expensive move to compensate. The required compensation for urban origin women would be on average as high as 13,000 rupees, whereas that for urban men would be on average around

Table 4 Monetary equivalents of locations, by gender and rural origin

\begin{tabular}{lccccc}
\hline & \multicolumn{2}{c}{ Rural } & & \multicolumn{2}{c}{ Urban } \\
\cline { 2 - 3 } \cline { 5 - 6 } & \multicolumn{1}{c}{ Male } & Female & & Male & Female \\
\hline Monthly pay equivalent needed to compensate a move to a 'Remote Village' & & \\
from Village/Small town & $3921^{*}$ & $5141^{* *}$ & & $6327^{* *}$ & $7696^{* *}$ \\
from Home village/town & $5860^{* *}$ & $10705^{* *}$ & & $7935^{* *}$ & $13227^{* *}$ \\
from District Capital & 1549 & $4750^{* *}$ & & $5388^{* *}$ & $8927^{* *}$ \\
\hline
\end{tabular}

Notes: 1 USD 50 Rupees. Calculated from the estimates in column 4 of Table 3. ****: significant at the $1 \%$ and $5 \%$ levels respectively, based on a Wald test (2-tailed). The calculation assumes general caste status, no children, and no teaching experience. 
8000 rupees. The size of the compensating differentials may appear large given that the teachers will in any case be employed within the same district, which is geographically not a vast area. However, in the state of Uttarakhand even short distances may take long to travel due to the geography of the state. Some robustness checks for the main estimations are presented in Appendix 4, and they show that the conclusions hold for both flat and mountainous districts in the state.

\subsection{Preferences of 'Para-teachers' vs 'Standard students'}

The results of the previous section indicate that location of origin is an important determinant of location preferences. The sample in the study includes former parateachers who were included in the training programme in 2010. These teachers were originally hired locally to teach in schools in rural areas and therefore 97 percent of them are of a rural origin. The aim of this section is not to address the broader question on the use of contract teachers, but simply to provide some indication of the potential implications for preferences of hiring individuals local to rural areas. ${ }^{13}$ Here it must be acknowledged that if hiring would be localised with permanent contracts, the pool of applicants, even in remote areas, might differ from the current para-teachers who entered the training programme. Due to the quotas, the standard students and para-teachers on average do not differ significantly from each other with respect to gender, or caste. Para-teachers naturally have more teaching experience as this was their selection criterion for the BTC programme.

Table 5 reports the results of three model specifications. The first two rely on a sample of both para-teachers and standard students. The third one reports results for a sample that only includes the former para-teachers. The first column shows the results of a model, where para-teacher status is interacted with the contract attributes. The model also includes interaction terms between the contract attributes and the core characteristics in which para-teachers differ with respect to the standard trainees; teaching experience, having children and a Master's degree. The results of this model specification suggest that para-teachers value their home location less than standard trainees, and as opposed to the standard trainees, para-teachers are indifferent between a remote location and the district capital. The para-teachers are also less concerned with merit-based transfers.

In the second column, an interaction term with the dummy variable for rural origin is added to the model specification in column [1]. The results show that the rural origin of former para-teachers is a key reason for why their location preferences differ from those of the other trainees. The interaction terms between the location attributes and para-teacher status are no longer statistically significant, while the interaction terms between the attributes and rural origin are. Similarly to the results on rural origin for the competitively selected trainees in Table 3, these results highlight one potential practical benefit of hiring teachers locally.

The third column shows the estimated preference parameters for para-teachers by gender, including a set of interactions between control variables and contract attributes. A key purpose of this exercise is to assess whether the gender effects present for standard trainees are also present for para-teachers. The results show that gender plays some role, but not necessarily as strongly as for the sample of standard students. Male para- 
Table 5 Comparison of the preferences of para-teachers and standard students Logit estimates of DCE model

\begin{tabular}{|c|c|c|c|c|c|c|}
\hline \multirow{3}{*}{$\begin{array}{l}\text { Contract attributes } \\
\text { Pay (1000 Rs.) }\end{array}$} & \multicolumn{2}{|l|}{ [1] } & \multicolumn{2}{|l|}{ [2] } & \multicolumn{2}{|l|}{ [3] } \\
\hline & \multicolumn{2}{|c|}{ Full sample } & \multicolumn{2}{|c|}{ Full sample } & \multicolumn{2}{|c|}{ Para only } \\
\hline & .127 & {$[.017]^{* *}$} & .124 & {$[.020]^{* *}$} & .091 & {$[.033]^{* *}$} \\
\hline Location: Village/Small town & .569 & {$[.148]^{* *}$} & .798 & {$[.173]^{* *}$} & .266 & {$[.294]$} \\
\hline Location: Home village / town & .989 & {$[.153]^{* *}$} & 1.264 & {$[.181]^{* *}$} & .104 & {$[.286]$} \\
\hline Location: District Capital area & .464 & {$[.151]^{* *}$} & .892 & {$[.178]^{* *}$} & -.159 & {$[.293]$} \\
\hline Contract: Permanent with rotation & .518 & {$[.106]^{* *}$} & .594 & {$[.124]^{* *}$} & 1.136 & {$[.207]^{* *}$} \\
\hline Contract: Permanent & .748 & {$[.157]^{* *}$} & .789 & {$[.186]^{* *}$} & 1.112 & {$[.304]^{* *}$} \\
\hline Transfers: Based on merit & .921 & {$[.117]^{* *}$} & .961 & {$[.139]^{* *}$} & .623 & {$[.222]^{* *}$} \\
\hline Small class size & -.005 & {$[.092]$} & -.067 & {$[.108]$} & -.090 & {$[.179]$} \\
\hline Para x Pay (1000 Rs.) & -.014 & {$[.016]$} & -.017 & {$[.017]$} & & \\
\hline Para $\times$ Village/Small town & -.071 & {$[.137]$} & .064 & {$[.147]$} & & \\
\hline Para $x$ Home village / town & -.310 & {$[.138]^{*}$} & -.155 & {$[.148]$} & & \\
\hline Para x District Capital area & -.487 & {$[.139]^{* *}$} & -.236 & [.149] & & \\
\hline Para $\times$ Permanent with rotation & -.036 & {$[.097]$} & .002 & {$[.105]$} & & \\
\hline Para $\times$ Permanent & -.084 & [.144] & -.068 & {$[.154]$} & & \\
\hline Para $\times$ Based on merit & -.339 & {$[.107]^{* *}$} & -.325 & {$[.115]^{* *}$} & & \\
\hline Para $\times$ Small class size & -.067 & {$[.085]$} & -.104 & {$[.091]$} & & \\
\hline Female x Pay (1000 Rs.) & & & & & -.058 & {$[.020]^{* *}$} \\
\hline Female $\times$ Village/Small town & & & & & .316 & {$[.172]$} \\
\hline Female $\times$ Home village / town & & & & & .385 & {$[.169]^{*}$} \\
\hline Female $\times$ District Capital area & & & & & .099 & {$[.173]$} \\
\hline Female $\times$ Permanent with rotation & & & & & -.513 & {$[.122]^{* *}$} \\
\hline Female $\times$ Permanent & & & & & -.360 & {$[.177]^{*}$} \\
\hline Female $\times$ Based on merit & & & & & .196 & {$[.131]$} \\
\hline Female $\times$ Small class size & & & & & .280 & {$[.106]^{* *}$} \\
\hline Rural x Pay (1000 Rs.) & & & .006 & {$[.016]$} & & \\
\hline Rural $\times$ Village/Small town & & & -.343 & {$[.133]^{* *}$} & & \\
\hline Rural $x$ Home village / town & & & -.406 & {$[.140]^{* *}$} & & \\
\hline Rural x District Capital area & & & -.643 & {$[.137]^{* *}$} & & \\
\hline Rural x Permanent with rotation & & & -.111 & {$[.095]$} & & \\
\hline Rural x Permanent & & & -.053 & {$[.144]$} & & \\
\hline Rural $\times$ Based on merit & & & -.052 & {$[.108]$} & & \\
\hline Rural x Small class size & & & .096 & {$[.084]$} & & \\
\hline Additional Controls & Yes & & Yes & & Yes & \\
\hline Individuals ; Responses & $671 ;$ & & $671 ; 7$ & & $266 ;$ & \\
\hline
\end{tabular}

$*^{*}, *$ : significant at the $1 \%$ and $5 \%$ levels respectively. Rural = dummy for rural origin (home location). In columns [1] and [2], the additional controls are dummy variables for teaching experience, for having children and for a MSc degree. In column [3] the additional variables are dummy variables for teaching experience, for having children, for a MSc degree and SC/ST/OBC. Omitted category for Location is 'Remote village', for Contract 'Fixed term 7-year contract', and for Transfers 'Based on connections/influence'.

teachers are entirely indifferent between the different locations with respect to a remote village. Female para-teachers prefer the village/small town category to a remote village $\left(\mathrm{H}_{0}: .266+.316=0, \mathrm{p}=.045\right)$, and prefer their home location to a remote village at the 10 percent significance level $\left(\mathrm{H}_{0}: .104+.385=0, \mathrm{p}=.085\right)$. They are indifferent 
between a remote village and the district capital. Female para-teachers value small class size more than men. They value pay relatively little, and the permanence of the position substantially less than men.

These results confirm that the former para-teachers, almost all of whom are rural, and were hired locally, are not averse to being employed in rural, or even remote areas, as opposed to urban areas. As opposed to female standard students, female parateachers do not have an equally pronounced preference for non-remote locations.

\section{Skills}

The surveyed students participated in a timed test of generic skills, which focused on the knowledge of countries, English, and Arithmetic. A detailed description of the tests can be found in Appendix 2. The test was not designed to test teaching skills as such, but to provide a measure of general knowledge that could be compared easily across teachers. However, the measure can be expected to be correlated with the subject knowledge expected of primary school teachers. To begin with the analysis of skills, Figure 1 below shows the distributions of the test scores across the full sample of both para-teachers and standard students.

There is some room for interpretation regarding what represents a "good" score in these tests for primary school teachers. In the Arithmetic test however, Figure 1 shows a hump at score 20 . This is generated by those respondents who were able to answer addition and subtraction questions (10 questions each), but were discouraged by multiplication or division (10 each). The full test can be found in Appendix 2, and it seems that a score of 20 , or below, could be considered a somewhat worrying result for a trainee.
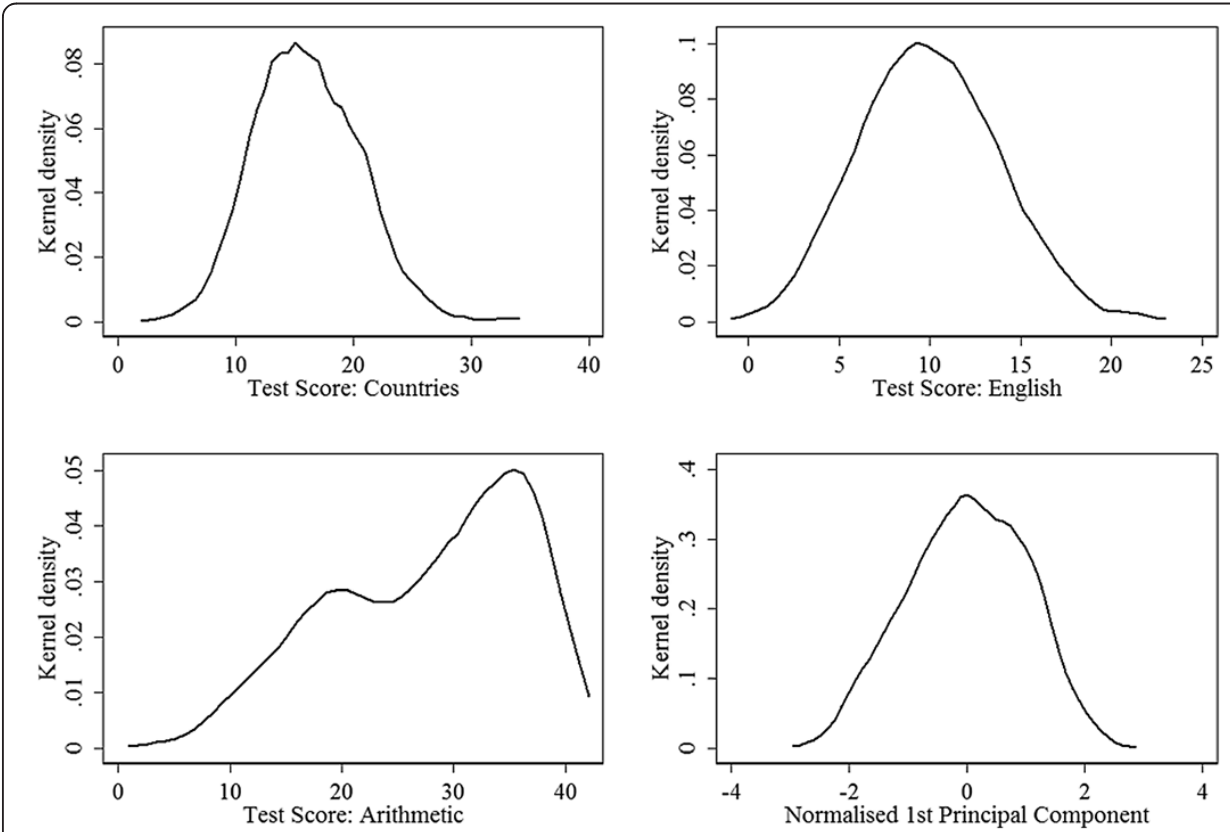

Figure 1 Distribution of scores in skill tests, kernel densities. Notes: Epanechnikov kernel densities, default STATA 12 bandwidths. The first Principal Component has correlations of $0.77,0.80$ and 0.83 with Countries, English and Arithmetic, respectively. 
The determinants of skills in our data are interesting for two reasons. Firstly, it is possible to assess to what extent the quotas for women and scheduled castes, and the preferential entry of former para-teachers, are reflected in our measure of skills. It is ex ante clear that the preferred groups will have obtained lower scores in the BTC entry exam, and should be expected to have lower skills, if there is a correlation between the entry score and our measure of skills. However, once this selection effect is controlled for, the relevance of other factors, can also be studied. Of primary interest to us are rural origin and education.

To begin with, Figure 2 shows the distributions of the normalised first principal component of the skill tests by key subgroups. It is apparent that despite large overlap, some differences in the group means do exist. To explore the determinants of skills more precisely, an OLS model is estimated, using the normalised first principal component of the three skill tests as the dependent variable. The model is estimated firstly for a sample of all trainees, and then separately for the standard students and the para-teachers. The results are shown in Table 6. The estimated coefficients can be interpreted in terms of standard deviations.

The regression results can be considered to conform with expectations. The results in the first column for the full sample show that the score for each of the quotafavoured groups is on average approximately half a standard deviation below that of the non-quota group. It is worth noting that one can belong to multiple favoured categories (ie. female and para-teacher).

Regarding the other observable characteristics (which are not primary selection criteria into the programme), in column 1 students from rural areas have lower skills, while a Masters degree is associated with higher skills. Older trainees do somewhat worse in our skills tests, while trainees with teaching experience do better. The last

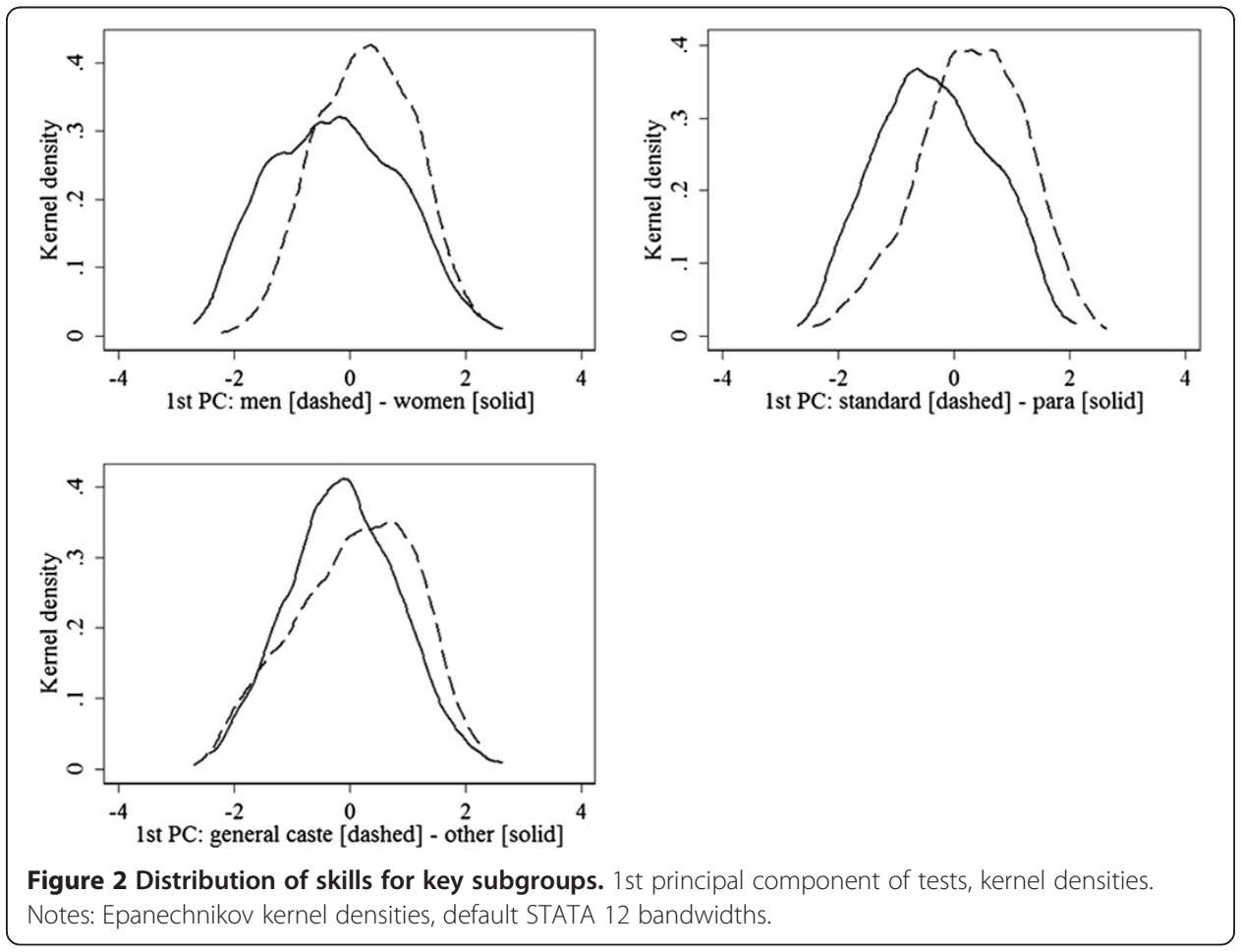


Table 6 Characteristics and skills, OLS

\begin{tabular}{lllllll}
\hline Sample: & \multicolumn{2}{l}{ All } & & \multicolumn{2}{l}{ Standard students } & \multicolumn{2}{l}{ Para-teachers } \\
\hline Rural & -.252 & {$[.088]^{* *}$} & -.151 & {$[.094]$} & -.535 & {$[.303]$} \\
MSC Degree & .192 & {$[.078]^{*}$} & .071 & {$[.109]$} & .219 & {$[.104]^{*}$} \\
Any children & -.160 & {$[.082]$} & -.181 & {$[.102]$} & -.104 & {$[.138]$} \\
Any experience & .218 & {$[.085]^{*}$} & .220 & {$[.087]^{*}$} & & \\
Age & -.044 & {$[.011]^{* *}$} & -.035 & {$[.015]^{*}$} & -.056 & {$[.015]^{* *}$} \\
Quota/favoured groups: & & & & & & \\
Female & -.627 & {$[.069]^{* *}$} & -.411 & {$[.090]^{* *}$} & -.936 & {$[.103]^{* *}$} \\
Para-teacher & -.477 & {$[.099]^{* *}$} & & & & \\
SC/ST/OBC & -.420 & {$[.071]^{* *}$} & -.551 & {$[.086]^{* *}$} & -.293 & {$[.143]^{*}$} \\
District effects & Yes & & Yes & & Yes & \\
Observations & 627 & & 392 & & 236 & .42 \\
R & .34 & & .23 & & \\
\hline
\end{tabular}

Notes: Dependent variable: Normalised 1st principal component of skills. ****: significant at the $1 \%$ and $5 \%$ levels respectively. SC/ST/OBC refers to a dummy for Scheduled Caste, Scheduled Tribe or Other Backward Caste.

result could be explained by the fact that we tested skills and knowledge that the trainees may have been teaching to their students recently.

Columns 2 and 3 show the results separately for the standard students and parateachers respectively. Among the standard students, women and lower caste trainees have statistically significantly lower skills. However, trainees of a rural origin do not differ in their skills with respect to trainees of an urban origin.

Among para-teachers, the scores of women in the skills test are nearly a whole standard deviation lower than the those of men. Also trainees from scheduled castes have lower skills, by 0.29 standard deviations. The dummy for rural origin is not statistically significant despite its large size due to the fact that there is very little variation in this variable in the para-teacher sample. Further, among para-teachers, those with a Masters degree are more skilled.

\section{Discussion and lessons for policy}

The key policy dilemma that the results of this study provide insights to concerns the recruitment and willingness of qualified teachers to work in remote areas. The study has focused on the preferences of teachers over locations as well as the heterogeneity and strength of these preferences. However, other contract attributes such as the type of contract, the determination of transfers and pupil-teacher ratio were also assessed, and controlled for. In drawing policy conclusions from the analysis of preferences, one has to assume, plausibly in our opinion, that the location preferences and effectiveness as a teacher are not independent of each other. In particular, the prevalent teacher absences in rural areas are likely to be connected with location preferences.

To our knowledge, this is the first discrete choice study of the preferences of developing country teachers. Some of the results, such as the unwillingness of women and individuals of an urban origin to enter rural jobs, have been established in earlier literature for health workers. This study extends the analysis of preferences by being more specific regarding the location and by adding more features of the job contract. In contrast with previous studies on public sector worker preferences, this study also measures 
skills, which allows one to assess the trade-offs present in hiring teachers with particular characteristics.

The main conclusion that emerges from the analysis is that the current selection quotas are unlikely to be optimal from the viewpoint of hiring motivated and qualified teachers to remote areas. The results also lend cautious support for a more decentralised hiring system, since this could lead to teachers being matched better with their preferred location.

The first conclusion can be justified considering the results on the preferences and skills of women and low-caste students. The results show that women, who currently have a 50 percent quota in teacher training in Uttarakhand, are found to have lower skills on average than men. The lower level of female skills that we observe is likely to stem from the fact that due to the female quota, female applicants have entered the training programme with lower entry scores. ${ }^{14}$ The 'remote village' location tends to be the least desirable location option, but particularly among the competitively selected students, women are substantially less willing to work in remote locations than men. Given that the starting salary of teachers in Uttarakhand was around 18,000 rupees, the estimates in Table 4 indicate that in the case of women in general, a salary increase of 26-73 percent would be required to compensate for a posting to a remote village, depending on the alternative location category and origin of the teacher. These estimates suggest that location is a highly important non-monetary component of the overall compensation for teachers in India. Women are also more averse than men towards permanent contracts with than without compulsory rotation, likely to be explained by responsibility for caring for the family. Compulsory transfers could be considered one mechanism to react to shortages of teachers in certain areas.

Teacher trainees from scheduled castes, tribes, and other backward classes are not found to have statistically significantly different preferences than general caste teachers in our sample. However, due to affirmative action, they are found to have significantly lower skills, by about half a standard deviation.

From the perspective of learning, gender and caste quotas may be defended with an assumption that pupils benefit from being taught by a teacher of their own kind. However, given the unwillingness of women to work in remote locations, it may be that despite the intention of the quota, girls in more remote schools end up being taught mainly by male teachers. As Table 7 shows, according to the DISE data for 2008, more

Table 7 Share of female and para-teachers in government primary schools in Uttarakhand by school remoteness, year 2008-09

\begin{tabular}{llllllll}
\hline & No. of & Teachers & Female & Para & & No source & Grade 1 \\
\hline Remoteness & schools & per school & share & share & Electricity & of water & enrollment \\
Urban & 387 & 3.166 & .735 & .031 & .407 & .059 & 10215 \\
Rural: & & & & & & & \\
Distance to HQ 0-10 km & 2820 & 2.628 & .604 & .095 & .245 & .079 & 41760 \\
Distance to HQ 11-20 km & 2968 & 2.296 & .496 & .147 & .168 & .114 & 31447 \\
Distance to HQ 21-40 km & 3843 & 2.106 & .467 & .198 & .111 & .122 & 33709 \\
Distance to HQ 40+ km & 1908 & 1.966 & .393 & .252 & .070 & .136 & 15027 \\
\hline
\end{tabular}

Notes: Source: DISE 2008-09. 'Distance to $\mathrm{HQ}^{\prime}$ is the distance to the block headquarters (Block is an administrative subunit of a district). A 'source of water' is either a tap, hand pump or a well. 'Para' share refers to the share of teachers, who are para-teachers. 
remote primary schools in Uttarakhand have a lower proportion of female teachers, and many of the female teachers have been locally hired para-teachers. In turn, teachers in urban schools are $74 \%$ female. This stylised fact regarding gender imbalance of teachers along the urban-rural gradient also applies to India as a whole, and is even somewhat worse than in Uttarakhand.

In the general section of our questionnaire, 52 percent of respondents agreed with a statement that the best way to place teachers into schools would be for teachers to apply independently to schools with localised hiring rather than placement based on the success on the BTC programme, or random allocation into schools. Our results on preferences also offer some support more decentralised hiring. The trainees typically rated their home town, or village as the most desirable place to be employed in as a teacher. Teachers of a rural origin are found to be more willing to work in remote locations, even after conditioning on other observable characteristics. There appears to be no significant drawback to rural origin teachers. Among standard students, their level of measured skills is not statistically significantly lower than that of urban origin teachers. In the full sample, teachers of a rural origin have lower skills, but this is driven by the inclusion of the former para-teachers, who are mostly rural. ${ }^{15}$

Regarding the para-teachers, our findings indicate that former para-teachers generally have lower skills than students selected through the traditional route. Further, parateacher women have considerably lower skills than para-teacher men. On average, para-teachers are not as averse to working in remote locations as other teachers. Women and men do not differ as significantly with respect to their location preferences. The results indicate that if decentralised hiring in more remote areas would mainly attract candidates who resemble the former para-teachers, there would be a better match between location preferences and actual location, but this would come at the cost of lower skills.

The results show that being able to work in their home village is of great value to female teachers. Therefore, again local hiring could succeed in staffing more remote schools with motivated women, although women on average might still have lower skills. If the current staffing policies continue, and female teachers are to be assigned to remote posts, the remaining option may be to try to increase the attractiveness the remote posts to women by other means. ${ }^{16}$

Overall, the results suggest that it would be possible to recruit teachers who are not only more skilled, but also more willing to work in remote locations, by relaxing the existing quotas, and possibly replacing them with quotas, or additional points for applicants from rural areas. They also offer some support for more decentralised hiring. Here it should however be noted that if hiring would be local, this might attract a pool of applicants that differs from that in our sample.

It is recognised that the overall impact of quotas evidently goes beyond the aspects studied here. Furthermore, as the quotas are typically set at the national level, there may be little room for state-level policy in this regard. The results are likely to be generalisable to the rest of the Indian states to the extent that in the other states a) the groups preferred by quotas have on average lower skills (and are thus benefiting from the quota), b) the groups preferred by quotas are not more willing to work in remote areas, and c) there are difficulties in staffing remote schools. These are not strong assumptions, and are likely to be true in most Indian states. 


\section{Endnotes}

${ }^{1}$ Based on the District Information System Data (DISE).

${ }^{2}$ Like many developing countries, Indian states have recruited temporary local contract teachers, in particular in more remote locations. These teachers generally lack teacher training and are paid significantly less than the formal teachers.

${ }^{3}$ This is possibly the most reliable source of nation-wide performance data on primary school students in India. More information is available at http://www.asercentre. org/

4.Provisional figures, see http://www.censusindia.gov.in/2011-prov-results/paper2/ prov_results_paper2_uttrakhand.html

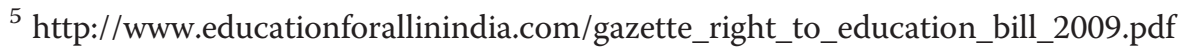

${ }^{6}$ The numbers are smaller (100) in the three "mini" DIETs.

${ }^{7}$ The SSA framework for implementation is available at http://ssa.nic.in/page_portletlinks?foldername $=$ ssa-framework

${ }^{8}$ Source: Communication with officials at Uttarakhand Sarva Shiksha Abhiyan office. The salary is indexed to consumer prices, and has thus increased since 2010.

${ }^{9}$ Rotation and compulsory service in rural areas after graduation have been common practices used for instance in the health sector in developing countries (see e.g. WHO, 2006).

${ }^{10}$ Béteille (2009) reports that half of the teachers she surveyed in three states agreed that transfers require connections and 30 percent believed that they would have to pay to obtain the post they wanted. Ramachandran et al. (2005) report that in 2005, the government in Rajasthan transferred 20,000 teachers. To quote the authors: 'Discussions with trade union leaders revealed that transfers and posting were big business in Rajasthan. Intensive lobbying followed bulk transfers and it was rumoured that political middlemen demanded Rs. 5,000 to Rs. 25,000 to cancel the transfer or ensure a good posting'.

${ }^{11}$ The overall marginal effects for women in column [1] of Table 3 are: Pay (1000 rs) .030 , Small town .168, Home .329, Capital .225, Permanent with rotation .118, Permanent without rotation .173, Merit-based transfers .281 and small class - .000 .

${ }^{12}$ A dummy variable for teaching experience is included instead of the actual years of teaching experience, since this allows for a larger number of observations. Some of the trainees reported to have teaching experience, but did not specify the number of years.

${ }^{13}$ There is an emerging literature on the effectiveness of contract teachers. In the Indian context, the limited evidence available suggests that despite lower pay, or lack of qualifications, para-teachers perform no worse than regular teachers in India and may even outperform them (see Atherton and Kingdon, 2010, Goyal and Pandey, 2009, Muralidharan and Sundararaman, 2010). Studies on contract teachers in other developing countries produce somewhat more mixed results (see e.g. Bourdon et al. 2010, de Laat and Vegas, 2005 and Duflo et al. 2012).

14 The Uttarakhand BTC application data is publicly available, and entrance test marks of applicants are somewhat lower for women than for men.

${ }^{15}$ It might be suspected that even if both para-teachers and standard students come from rural areas, the para-teachers would be from more remote locations.

${ }^{16}$ According to the national SSA framework for implementation 'The provision of $50 \%$ female teachers has been effective in bringing large numbers of women into the 
education system. However, the problems faced by female teachers need to be given due recognition. Female teachers should be supported to overcome security

17 This scoring method was based on the convenience of not having to go through hundreds of responses in two languages. Based on responses given in English, this does not appear to be a concern - only a few respondents gave occasional responses that were not actual countries, such as "Rome" or "Taliban".

${ }^{18}$ It was assumed that each level improvement within an attribute increases the utility by the same amount compared to the lower level (with reference to Equation 4, fixed term contract gets $\beta=1$, permanent with rotation gets $\beta=2$, Permanent without rotation $\beta=3$ and so on).

\section{Appendix 1 Data collection}

The research team visited the teacher training centres (DIETs) of 7 districts out of 13 in the state in May 2010 (see Figure 3). 120 survey questionnaires were printed for each school with the aim of randomly sampling $50 \%$ of both standard students and parateachers from each district, or having roughly 50 para-teachers and 50 standard students from each district. Table 8 shows the final sample sizes, and how the randomisation of students was carried out.

\section{Appendix 2 Skills tests}

As part of the survey, the teacher students filled a voluntary three-part timed skills test. The parts are referred to here as Countries, English and Arithmetic. The tests were

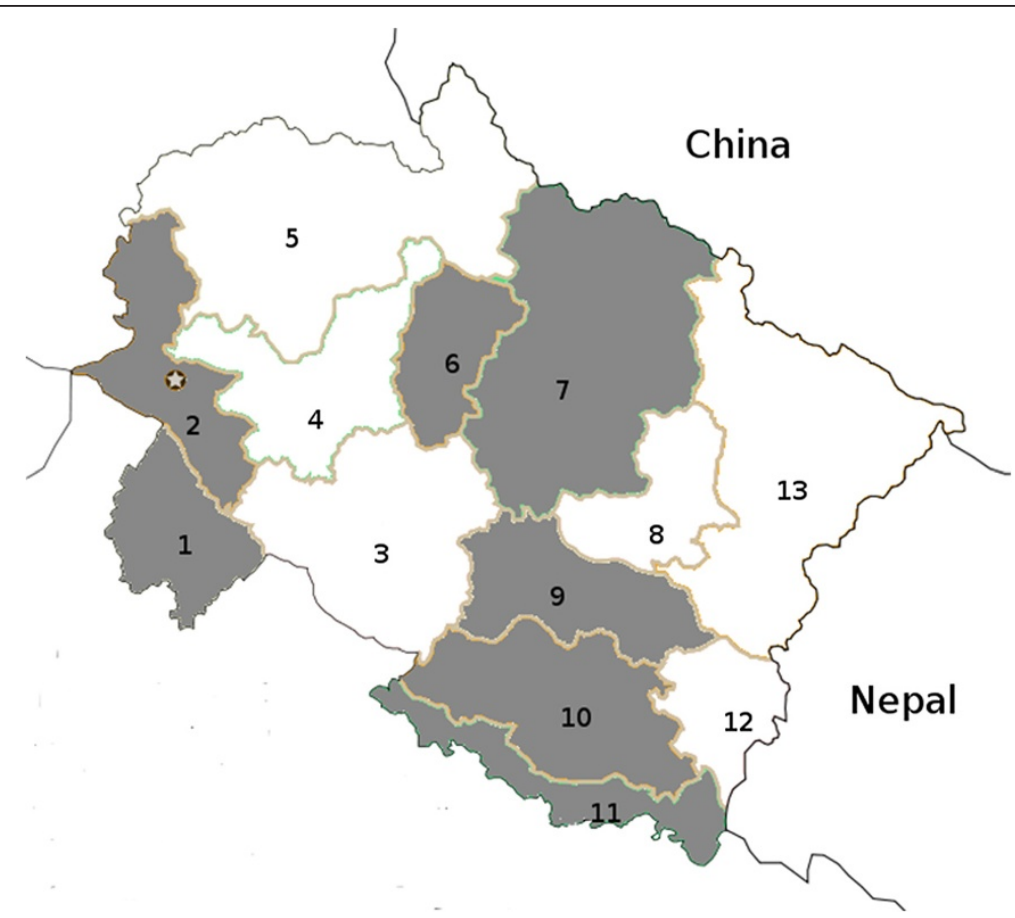

Figure 3 Districts of Uttarakhand, including sampled districts. Notes: The sampled districts (1, 2, 6, 7, 9, 10, 11) are shaded. (1) Haridwar, (2) Dehradun, (3) Tehri Garhwal, (4) Tehri, (5) Uttarkashi, (6) Rudraprayag, (7) Chamoli, (8) Bageshwar, (9) Almora, (10) Nainital, (11) Udham Singh Nagar, (12) Champawat, (13) Pithoragarh. Map source: Wikimedia Commons. GNU Free Documentation Licence. 
Table 8 Sample size and notes on data collection

\begin{tabular}{|c|c|c|c|c|}
\hline \multicolumn{5}{|c|}{ Sample sizes } \\
\hline District & $\begin{array}{l}\text { Standard } \\
\text { students }\end{array}$ & $\begin{array}{l}\text { Para- } \\
\text { teachers }\end{array}$ & Randomisation & Notes on conditions \\
\hline Almora & 43 & 49 & $\begin{array}{l}50 \% \text { of both groups randomised from } \\
\text { student register }\end{array}$ & Chairs, but no tables. \\
\hline Chamoli & 62 & 56 & $\begin{array}{l}\text { Questionnaires distributed in classrooms in } \\
\text { random fashion }\end{array}$ & $\begin{array}{l}\text { Standard students had } \\
\text { chairs, no tables. Para- } \\
\text { teachers sat on the floor. }\end{array}$ \\
\hline Dehradun & 51 & 41 & $\begin{array}{l}50 \% \text { of both groups randomised from } \\
\text { student register }\end{array}$ & $\begin{array}{l}\text { Most students had chairs } \\
\text { and tables, some just chairs. }\end{array}$ \\
\hline Haridwar & 63 & 43 & $\begin{array}{l}50 \% \text { of both groups randomised by staff, } \\
\text { criteria unknown. }\end{array}$ & Chairs, but no tables. \\
\hline Nainital & 50 & 47 & $\begin{array}{l}50 \% \text { of both groups randomised by staff, } \\
\text { criteria unknown. }\end{array}$ & Chairs and tables. \\
\hline Rudraprayag & 86 & 0 & $\begin{array}{l}\text { All standard students present were included. } \\
\text { Only } 8 \text { para-teachers enrolled in the school, } \\
\text { and thus not covered. }\end{array}$ & Chairs, but no tables. \\
\hline $\begin{array}{l}\text { Udham } \\
\text { Singh Nagar }\end{array}$ & 71 & 42 & $\begin{array}{l}\text { All standard students present included, half } \\
\text { of para-teachers covered (one randomly } \\
\text { selected classroom out of two). }\end{array}$ & Chairs and tables. \\
\hline Total & 426 & 278 & & \\
\hline
\end{tabular}

designed so that it would not consume much time and would be easy to implement in different conditions, and would leave as little room as possible for cheating. Questionnaires were bilingual (English + Hindi), and instructions were given in English and Hindi prior to each skill test. Each component of the test will be discussed below and the average scores for each test will be shown in Table 9 below.

In the 'Countries' test, the students were asked to write down as many countries as they could in 90 seconds. This test would be classified in research literature as a test of semantic fluency. The origins of such a test can be traced to Thurstone's Word Fluency Test for verbal ability Thurstone (1938). It may be useful in the examination of, for example, language, executive functioning, and speed of information processing. It has been found that education and age have an impact on the number of items written down, whereas gender usually has only a small effect (Ratcliff et al. 1998). In our context, this can be seen as a test of general knowledge, verbal skills, and a proxy for the quality of education. In the test, the trainees could use any language they wished, and most used Hindi, while some used English. The students were not told that they should write down the names of countries prior to the beginning of the test, but simply "items from an announced category". An example using animals was given. The scoring of the test was based on the number of items written down, regardless of whether they were real countries or not. ${ }^{17}$ The average score across 704 responses was 16.03 .

In the 'English' test, the students had to first write down as many English words beginning with an " $\mathrm{F}$ " as they could in 60 seconds, and next, as many beginning with an

Table 9 Summary scores of the three skills components

\begin{tabular}{llllll}
\hline & Obs. & Mean & S.D. & Min & Max \\
\hline Countries & 704 & 16.04 & 4.40 & 3 & 33 \\
English & 702 & 9.96 & 3.82 & 0 & 22 \\
Arithmetic & 696 & 27.71 & 8.64 & 3 & 40 \\
\hline
\end{tabular}


"S" as they could in 60 seconds. This test has a similar origin as the 'Countries' test as a measure of verbal fluency, but it is typically applied to people in their native language. As in our case virtually all respondents are native Hindi speakers, the tests serve as an ad-hoc test for English vocabulary (for discussion on mono- and bilingual respondents, see Rosselli et al. 2002). The scoring was based on the average number of proper nouns for the two letters, allowing for minor spelling mistakes. Numbers only up to 10 ('Four', 'Five, 'Six,' 'Seven') were accepted. The correlation between the two sets of produced words was 0.74 across 702 respondents. The average combined score was 9.96.

The 'Arithmetic' test consisted of 40 calculations based on addition, subtraction, multiplication and division, at an increasing order of difficulty. The problems should be relatively easy for a person who is familiar with and seasoned in arithmetic computations, such as primary school teachers. The respondents were given 4 minutes to complete the test. They were not allowed to use a calculator, but could use scrap paper and a pen to perform the calculations. The average number of solved calculations for 696 responses was 27.71 and 16 respondents achieved the full score of 40 . The test is shown in Figure 4.

The correlation coefficient between the scores for the English and the Countries tests was 0.40, the Countries and Arithmetic tests 0.47 and English and Arithmetic test 0.51. As a measure of skills, the first principal component of the scores for the three tests was constructed and normalised to have a mean of zero and a standard deviation of one. Table 10 shows the correlation coefficients between the scores for each sub-test and the first principal component.

\section{Appendix 3 Design of the Discrete Choice Experiment}

In this study the job contracts have five attributes, and the attributes have two to four levels as follows: a) Pay: 0 - "Rs. 13000 per month", 1 - "Rs. 17000 per month", 2 - "Rs. 21000 per month". b) Location: 0 - "Remote village", 1 - "Village / Small town", 2 "Your home village / town", 3 - "District capital area". c) Contract: 0 - "Fixed term contract, renewable every 7 years", 1 - "Permanent, must transfer every 7 years, 2 - "Permanent, possibility to transfer after 7 years". d) Transfers: 0 - "Depend on connections and influence", 1 - "Depend on merit". e) Staff and pupils: 0 - "2 teachers, 14 pupils", 1 " 2 teachers, 75 pupils".

These attributes and levels were chosen after consulting a number of academics and policy makers in Delhi, as well as officials in states of Uttarakhand, Himachal Pradesh and Punjab, many of whom were former teachers. The study by Ramachandran et al. 2005 also provided useful background information. Sample page is provided in Figure 5.

Thus, there are total of 144 possible contracts arising from combinations $\{a 0, a 1, a 2\} \times$ $\{\mathrm{b} 0, \mathrm{~b} 1, \mathrm{~b} 2, \mathrm{~b} 3\} \times\{\mathrm{c} 0, \mathrm{c} 1, \mathrm{c} 2\} \times\{\mathrm{d} 0, \mathrm{~d} 1\} \times\{\mathrm{e} 0, \mathrm{e} 1\}$. Further, there are a total of $(144 \times 144-$ 144) $/ 2=10296$ possible contract pair comparisons.

Out of the 10296 possible contract pairs, 12 pairs were selected using the principles from the literature on DCEs. Mangham et al. 2009 provide a practical primer, whereas a good theoretical starting point is Street et al. 2005

Out of the 144 possible contracts (full factorial), a fractional factorial of 24 contracts is first selected. This is a sub-group for which the levels of attributes are orthogonal. These 24 contracts are shown in Table 11. An orthogonal fractional factorisation 


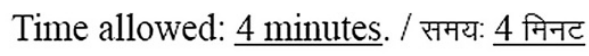

Solve as many as you can. Calculators are not allowed. आप जितने अधिक प्रश्न हल कर सकते हों, करें। कैलकुलेटर के प्रयोग की अनुमति नहीं है।

$16+25=$

$14+87=$

$34-15=$

$43-17=$

$87-53=$

$62+52=$

$42-29=$

$59+31=$

$32+17=$

$87-74=$

$18: 3=$

$6 * 7=$

$80: 5=$

$4 * 13=$

$5 * 13=$

$52: 4=$

$23 * 3=$

$96: 4=$

$66: 3=$

$43 * 3=$
$632+244=$

$522-245=$

$366+241=$

$753-283=$

$279+245=$

$846-639=$

$2247+473=$

$472-183=$

$652+573=$

$470-265=$

$42 * 11=$

$22 * 7=$

$240: 15=$

$492: 12=$

$37 * 21=$

$44 * 52=$

$861: 3=$

$536: 8=$

$27 * 67=$

$72 * 86=$

Figure 4 Test for Arithmetic. Notes: The actual size of the test was A4.

guarantees two desirable properties for the DCE: Orthogonality - attributes of the design are independent of each other, and level balance - that each attribute level appears in the design with equal likelihood (Mangham et al. 2009).

Combining the 24 contracts into 12 pairs randomly should produce unbiased estimates of the $\beta$ and $\delta$ parameters in equation 4. However, random pairing is likely to produce a design with low efficiency, or larger than necessary standard errors for the estimated parameters.

To improve the efficiency of the estimates, two further principles can be applied: Minimal overlap and utility balance (Huber and Zwerina, 1996). The former states that more information can be inferred with a DCE if the levels of attributes within a choice set are different (in our case between contracts A and B). The latter principle states that the efficiency can be improved by using some prior assumptions about the true parameters, and setting the choices within the choice set to have similar overall utility. 
Table 10 Correlation of the first principal component with the test scores

\begin{tabular}{ll}
\hline Subtest & Correlation with 1st PC \\
\hline Arithmetic & .83 \\
English & .80 \\
Countries & .77 \\
\hline
\end{tabular}

It has also been argued that the techniques for improving the efficiency may not be very important as sample size can substitute for an inefficient experimental design (Lusk and Norwood, 2005).

In this study, 12 contract pairs (choice sets) were selected from the 24 contracts using an improvised 'Monte Carlo' type approach: The 24 contracts were combined into 12 matched pairs repeatedly by an algorithm that attempted to minimise the overlap of

1) Please consider the following job opportunities:/ृृपया निम्नलिखित नौकरी के अवसरों पर विचार करें:

\begin{tabular}{|l|l|}
\hline & \multicolumn{1}{|c|}{ Job A } \\
\hline $\begin{array}{l}\text { Pay } \\
\text { वेतन }\end{array}$ & $\begin{array}{l}\text { Rs. 17000 per month } \\
17000 \text { रुपए प्रतिमाह }\end{array}$ \\
\hline $\begin{array}{l}\text { Location } \\
\text { स्थान }\end{array}$ & $\begin{array}{l}\text { Your home village / town } \\
\text { आपका गांव / कर्वा }\end{array}$ \\
\hline $\begin{array}{l}\text { Contract } \\
\text { नौकरी का अनुवंध }\end{array}$ & $\begin{array}{l}\text { Permanent, possibility to transfer after 7 years } \\
\text { स्थाई. और 7 वर्ष वाद स्थानातंरण की संभावना }\end{array}$ \\
\hline $\begin{array}{l}\text { Transfers } \\
\text { स्थानांतरण }\end{array}$ & $\begin{array}{l}\text { Depend on connections and influence } \\
\text { सिफारिश और पहुंच पर आधारित }\end{array}$ \\
\hline $\begin{array}{l}\text { Staff and pupils } \\
\text { स्टाफ और छात्रों की संख्या }\end{array}$ & $\begin{array}{l}\text { 2 teachers, 75 pupils } \\
2 \text { शिक्षक. 75 छात्र }\end{array}$ \\
\hline
\end{tabular}

\begin{tabular}{|l|l|}
\hline & \\
\hline $\begin{array}{l}\text { Pay } \\
\text { वेतन }\end{array}$ & $\begin{array}{l}\text { Rs. 21000 per month } \\
21000 \text { रुपए प्रतिमाह }\end{array}$ \\
\hline $\begin{array}{l}\text { Location } \\
\text { स्थान }\end{array}$ & $\begin{array}{l}\text { Remote village } \\
\text { कोई दूरस्थ गांव }\end{array}$ \\
\hline $\begin{array}{l}\text { Contract } \\
\text { नौकरी का अनुवंध }\end{array}$ & $\begin{array}{l}\text { Fixed term contract, renewable every 7 years } \\
\text { निश्चित अवधि का अनुवंध, जिसका हर 7 वर्ष वाद नवीकरण किया जा सकता ह }\end{array}$ \\
\hline $\begin{array}{l}\text { Transfers } \\
\text { स्थानांतरण }\end{array}$ & $\begin{array}{l}\text { Depend on connections and influence } \\
\text { सिफारिश और पहुंच पर आधारित }\end{array}$ \\
\hline $\begin{array}{l}\text { Staff and pupils } \\
\text { स्टाफ और छात्रों की संख्या }\end{array}$ & $\begin{array}{l}\text { 2 teachers, 14 pupils } \\
\text { 2 शिक्षक, 14 छात्र }\end{array}$ \\
\hline
\end{tabular}

\section{Given a choice, which of the above opportunities would you} choose? Please circle:

\section{Job A / Job B}

यदि आपको अपनी पसंद चुनने का विकल्प दिया जाए, तो ऊपर दिए गए अवसरों में से आप किसे चुनेंगे? कृपया नीचे अपनी पसंद पर गोले का निशान लगाएं:

\section{नौकरी $\mathrm{A}$ / नौकरी B}

Figure 5 Sample page of the DCE. Notes: The actual size of the page was A4. 
Table 11 Orthogonal 24-fractional factorial

\begin{tabular}{llllllllllll}
\hline Contract number & \multicolumn{1}{l}{ Attributes } & \multicolumn{1}{c}{ Contract number } & Attributes \\
\hline $\mathbf{1}$ & $\mathbf{a}$ & $\mathbf{b}$ & $\mathbf{c}$ & $\mathbf{d}$ & $\mathbf{e}$ & & $\mathbf{a}$ & $\mathbf{b}$ & $\mathbf{c}$ & $\mathbf{d}$ & $\mathbf{e}$ \\
$\mathbf{2}$ & 0 & 0 & 1 & 0 & 0 & $\mathbf{1 3}$ & 0 & 2 & 1 & 0 & 0 \\
$\mathbf{3}$ & 0 & 0 & 1 & 1 & 1 & $\mathbf{1 4}$ & 0 & 2 & 1 & 1 & 1 \\
$\mathbf{4}$ & 1 & 0 & 0 & 1 & 1 & $\mathbf{1 5}$ & 1 & 2 & 0 & 1 & 1 \\
$\mathbf{5}$ & 1 & 0 & 2 & 0 & 0 & $\mathbf{1 6}$ & 1 & 2 & 2 & 0 & 0 \\
$\mathbf{6}$ & 2 & 0 & 0 & 0 & 1 & $\mathbf{1 7}$ & 2 & 2 & 0 & 0 & 1 \\
$\mathbf{7}$ & 2 & 0 & 2 & 1 & 0 & $\mathbf{1 8}$ & 2 & 2 & 2 & 1 & 0 \\
$\mathbf{8}$ & 0 & 1 & 0 & 1 & 0 & $\mathbf{1 9}$ & 0 & 3 & 0 & 1 & 0 \\
$\mathbf{9}$ & 0 & 1 & 2 & 0 & 1 & $\mathbf{2 0}$ & 0 & 3 & 2 & 0 & 1 \\
$\mathbf{1 0}$ & 1 & 1 & 0 & 0 & 0 & $\mathbf{2 1}$ & 1 & 3 & 0 & 0 & 0 \\
$\mathbf{1 1}$ & 1 & 1 & 2 & 1 & 1 & $\mathbf{2 2}$ & 1 & 3 & 2 & 1 & 1 \\
$\mathbf{1 2}$ & 2 & 1 & 1 & 1 & 0 & $\mathbf{2 3}$ & 2 & 3 & 1 & 1 & 0 \\
\hline
\end{tabular}

Contract number and attribute levels.

attribute levels between pairs. A set of the resulting "low-overlap" pairings (i.e. different sets of 12 pairs) was used to simulate choices for 500 respondents with identical utility functions but individual error terms (corresponding to the random utility model). ${ }^{18}$ These choices were then predicted with a Logit model, and the precision of the estimates was evaluated (the larger the determinant of the information matrix, the more precise).

The process led us to choose the following set of contract number pairings (Contract A, Contract B): (16,5), (9,1), (24,7), (15,6), (10,17), (12,19), (22,18), (21,2), (4,14), (11,20), $(3,13),(23,8)$. Table 12 below shows the actual choices of the respondents. There were no pairs (choice sets) for which a certain option would have always been preferred (either only A, or only B).

\section{Appendix 4 Robustness checks}

This section reports on a set of robustness checks regarding the consistency of the discrete choice experiment. Table 13 below reports the results of a number of

Table 12 Frequency of choices in the DCE

\begin{tabular}{lllll}
\hline $\mathbf{A}, \mathbf{B})$ & Choose $\mathbf{A}$ & Choose B & Non-response & \% Non-response \\
\hline$(16,5)$ & 514 & 172 & 21 & 3,1 \\
$(9,1)$ & 426 & 259 & 22 & 3,2 \\
$(24,7)$ & 421 & 267 & 19 & 2,8 \\
$(15,6)$ & 300 & 390 & 17 & 2,5 \\
$(10,17)$ & 484 & 202 & 21 & 3,1 \\
$(12,19)$ & 427 & 259 & 21 & 3,1 \\
$(22,18)$ & 176 & 511 & 20 & 2,9 \\
$(21,2)$ & 258 & 424 & 25 & 3,7 \\
$(4,14)$ & 204 & 476 & 27 & 4 \\
$(11,2)$ & 601 & 82 & 24 & 3,5 \\
$(3,13)$ & 315 & 362 & 30 & 4,4 \\
$(23,8)$ & 566 & 114 & 27 & 4 \\
\hline
\end{tabular}


estimations for the sample of standard students, which can be compared with the main results, originally shown in column 1 of Table 3 .

If for any reason, for instance due to the order of placement on the questionnaire, respondents would have a tendency to choose the A option in the DCE either with a higher, or a lower, probability than B, the results could be biased. This can be easily tested by including a constant in the model. The model in column [1] in Table 13 shows that a constant is not statistically significant and does not affect the results.

One potential disadvantage of discrete choice experiments in relation to contingent valuation is the cognitive complexity of the task for the respondents. It is possible that to simplify the task, some respondents use rules of thumb, such as lexicographic ordering, to make their choices (Hanley et al. 2001). Column [2] in Table 13 excludes a subset of respondents for whom we find lexicographic preferences, i.e. that they always prefer a certain contract attribute. This could also reflect strategic behaviour. In the full sample the tendency to exhibit such a preference is strongest regarding the "meritbased transfers" option; 57 respondents always choose a contract with this attribute when it's an option. Strict preferences for other attributes were much less frequent. Lancsar and Louviere 2006 argue against deleting respondents with lexicographic preferences, since theoretically, a random utility model may be able to cope with such preferences, and information is being lost. In our case, the estimates remain qualitatively very similar when individuals with lexicographic preferences are removed from the sample.

Table 13 Robustness checks of the DCE Model

\begin{tabular}{|c|c|c|c|c|c|c|c|c|}
\hline \multirow{3}{*}{$\begin{array}{l}\text { Contract attributes } \\
\text { Pay (1000 Rs.) }\end{array}$} & \multirow{2}{*}{\multicolumn{2}{|c|}{$\begin{array}{c}\text { [1] } \\
\text { ncluding } \\
\text { constant }\end{array}$}} & \multirow{2}{*}{\multicolumn{2}{|c|}{$\begin{array}{c}\text { [2] } \\
\text { Excluding } \\
\text { lexicographic }\end{array}$}} & \multirow{2}{*}{\multicolumn{2}{|c|}{$\begin{array}{c}\text { [3] } \\
\text { Lowland } \\
\text { districts }\end{array}$}} & \multirow{2}{*}{\multicolumn{2}{|c|}{$\begin{array}{c}\text { [4] } \\
\begin{array}{c}\text { Mountain } \\
\text { districts }\end{array} \\
\end{array}$}} \\
\hline & & & & & & & & \\
\hline & .131 & {$[.013]^{* *}$} & .136 & {$[.012]^{* *}$} & .147 & {$[.017]^{* *}$} & .122 & {$[.015]^{* *}$} \\
\hline Location: Village/Small town & .491 & {$[.109]^{* *}$} & 609 & {$[.102]^{* *}$} & .532 & {$[.145]^{* *}$} & .489 & {$[.127]^{* *}$} \\
\hline Location: Home village / town & .651 & {$[.097]^{* *}$} & .733 & {$[.102]^{* *}$} & .879 & {$[.149]^{* *}$} & .498 & {$[.123]^{* *}$} \\
\hline Location: District Capital area & .349 & {$[.114]^{* *}$} & .467 & {$[.104]^{* *}$} & .464 & {$[.148]^{* *}$} & .299 & {$[.127]^{*}$} \\
\hline Contract: Permanent with rotation & .673 & {$[.068]^{* *}$} & .796 & {$[.073]^{* *}$} & .695 & {$[.104]^{* *}$} & .657 & {$[.090]^{* *}$} \\
\hline Contract: Permanent & .775 & {$[.104]^{* *}$} & .850 & {$[.107]^{* *}$} & .906 & {$[.157]^{* *}$} & .699 & {$[.131]^{* *}$} \\
\hline Transfers: Based on merit & .936 & {$[.076]^{* *}$} & .811 & {$[.081]^{* *}$} & 1.023 & {$[.115]^{* *}$} & .884 & {$[.098]^{* *}$} \\
\hline Small class size & -.133 & {$[.062]^{*}$} & -.103 & {$[.064]$} & -.087 & {$[.092]$} & -.158 & {$[.079]^{*}$} \\
\hline Female x Pay (1000 Rs.) & -.007 & {$[.016]$} & .004 & {$[.017]$} & -.008 & {$[.025]$} & -.002 & {$[.021]$} \\
\hline Female $\times$ Village/Small town & .186 & {$[.134]$} & .152 & {$[.144]$} & .326 & {$[.207]$} & .088 & {$[.177]$} \\
\hline Female $\times$ Home village / town & .703 & {$[.141]^{* *}$} & .821 & {$[.160]^{* *}$} & .987 & {$[.239]^{* *}$} & .582 & {$[.178]^{* *}$} \\
\hline Female x District Capital area & .561 & {$[.138]^{* *}$} & .532 & {$[.150]^{* *}$} & .619 & {$[.217]^{* *}$} & .534 & {$[.181]^{* *}$} \\
\hline Female $\times$ Permanent with rotation & -.185 & {$[.096]$} & -.229 & {$[.104]^{*}$} & -.192 & [.149] & -.181 & {$[.127]$} \\
\hline Female $\times$ Permanent & -.065 & {$[.145]$} & -.006 & {$[.162]$} & .111 & {$[.241]$} & -.116 & [.185] \\
\hline Female $\times$ Based on merit & .222 & {$[.109]^{*}$} & .231 & {$[.120]$} & .266 & {$[.173]$} & .229 & [.141] \\
\hline Female $\times$ Small class size & .126 & {$[.085]$} & .172 & {$[.092]$} & -.012 & {$[.130]$} & .235 & {$[.112]^{*}$} \\
\hline Constant & -.017 & {$[.054]$} & & & & & & \\
\hline Observations & 4793 & & 4097 & & 2085 & & 2708 & \\
\hline
\end{tabular}

***, : significant at the $1 \%$ and $5 \%$ levels respectively. Lowland districts are Haridwar, Dehradun and Udham Singh Nagar. Mountain districts are Rudraprayag, Chamoli, Almora, and Nainital. Omitted category for Location is 'Remote village', for Contract 'Fixed term 7-year contract', and for Transfers 'Based on connections/influence'. 
There may be a concern that the mountainous nature of Uttarakhand makes it an unrepresentative state in India and that this may affect the results, especially with respect to how different geographic locations are valued. This is addressed in columns [3] and [4], which show the results with separate sub-samples for lowland districts (Haridwar, Dehradun, Udham Singh Nagar) and mountain districts (Rudraprayag, Chamoli, Almora, Nainital). A comparison of the results in columns [3] and [4] suggests that the aversion or remote villages is somewhat stronger in the lowland districts, and this applies especially to women. This supports the generalisability of the results to rest of India, which is geographically more similar to the lowland districts.

\section{Competing interests}

The IZA Journal of Labor \& Development is committed to the IZA Guiding Principles of Research Integrity. The authors declare that they have observed these principles.

\section{Acknowledgements}

The authors would like to thank STICERD, London School of Economics and Political Science, for funding this project. Invaluable advice and support was provided to us by the helpful staff of the Uttarakhand DIETs and Dr Navin Kabadwal of SCERT Uttarakhand. We would like to thank Kunwar Singh Rawat of SSA Uttarakhand, Professors Arun Mehta and K. Sudha Rao of NUEPA, Professor Mohammad Akhtar Siddiqui of NCTE, Professor AK Jalalluddin, as well as Gautam Malik of SCERT Punjab and the staff at SCERT Himachal Pradesh for very useful discussions prior to collecting the data. We would like to thank participants at the CEP Labour Market seminar, RES conference 2011, ISI Annual Conference on Economic Growth and Development 2010, the Nordic Development Economics Conference 2011 and the Institute of Education seminar for helpful comments.

Responsible editor David Lam

Received: 22 May 2012 Accepted: 10 September 2012

Published: 29 November 2012

References

Adamowicz W, Louviere J, Williams M (1994) Combining Revealed and Stated Preference Methods for Valuing Environmental Amenities. J Environ Econ Manag 26(3):271-292

Atherton P, Kingdon G (2010) The Relative Effectiveness and Costs of Contract and Regular Teachers in India, Centre for the Study of African Economies Working Paper 15. University of Oxford, Oxford, UK

Banerjee AV, Banerji R, Duflo E, Glennerster R, Khemani S (2010) Pitfalls of Participatory Programs: Evidence From a Randomized Evaluation in Education in India. Am Econ J: Econ Policy 2(1):1-30

Banerji R, Kingdon G (2010) How Sound are Our Mathematics Teachers? Insights from the SchoolTELLS Survey, Learning Curve, issue XIV Azim Premji Foundation. March, Bangalore

Bhattacharjea S, Wadhwa W, Banerji R (2011) Inside Primary Schools A Study of Teaching and Learning in Rural India. ASER report. Pratham Mumbai Education Initiative, Delhi

Beaman L, Duflo E, Pande R, Topalova P (2012) Female Leadership Raises Aspirations and Educational Attainment for Girls: A Policy Experiment in India. Science 335(6068):582-586

Béteille T (2009) Absenteeism, Transfers and Patronage: The Political Economy of Teacher Labor Markets in India. PhD dissertation. Stanford University, Stanford, CA

Bourdon J, Frölich M, Michaelowa K (2010) Teacher Shortages, Teacher Contracts, and Their Effects on Education in Africa. J R Stat Soc 173(1):93-116, Series A

Boyd D, Lankford H, Loeb S, Wyckoff J (2010) Analyzing Determinants of the Matching of Public School Teachers to Jobs: Disentangling the Preferences of Teachers and Employers. Working Paper, Stanford University, Center for Education Policy and Analysis, forthcoming. J Labor Econ

Boyd D, Lankford H, Loeb S, Ronfeldt M, Wyckoff J (2011) The Role of Teacher Quality in Retention and Hiring: Using Applications to Transfer to Uncover Preferences of Teachers and Schools. J Policy Anal Manage 30(1):88-110

Cho H (2012) The Effect of Teacher-Student Gender Matching: Evidence from OECD countries. Econ Educ Rev 31(3):54-67

Chomitz KM, Setiadi G, Azwar A, Widiyarti NI (1998) What Do Doctors Want? World Bank Policy Research Working Paper 1888. Washington, D.C

Dee T (2005) A Teacher Like Me: Does Race, Ethnicity or Gender Matter? Am Econ Rev 95(2):158-165

Dee T (2007) Teachers and Gender Gaps in Student Achievement. J Hum Resour 42(3):528-554

De Laat J, Vegas E (2005) Do Differences in Teacher Contracts Affect Student Performance? Evidence from Togo. Unpublished mimeo, Department of Economics, Brown University, Providence, Rl

Diamond PA, Hausman JA (1994) Contingent Valuation: Is Some Number Better than No Number? J Econ Perspect $8(4): 45-64$

Duflo E, Hanna R, Ryan SP (2010) Incentives Work: Getting Teachers to Come to School, CEPR Discussion Paper 6682 Forthcoming in American Economic Review

Duflo E, Dupas P, Kremer M (2012) School Governance, Teacher Incentives and Pupil-Teacher Ratios: Experimenta Evidence from Kenyan Primary Schools. NBER Working Paper 17939, Cambridge, Massachusetts

Glewwe P, Kremer M, Ilias N (2010) Teacher Incentives. Am Econ J: Appl Econ 2(3):205-227

Godiyal S, Nautiyal RC (2008) Status of Teacher Education in Uttarakhand. E-journal India Assoc Educ Res 20(1-2):9 
Goyal S, Pandey P (2009) Contract Teachers. Report 28. South Asia Human Development Sector, World Bank, Washington D.C

Guttman R, Castle R, Fiebig DG (2009) Use of Discrete Choice Experiments in Health Economics: An Update of the Literature. CHERE Working Paper 2009/2. University of Technology, Sydney

Hanley N, Mourato S, Wright RE (2001) Choice Modelling Approaches: A Superior Alternative for Environmental Valuation? J Econ Surv 15(3):435-462

Hanson K, Jack W (2010) Designing Incentives for Rural Health Workers. In: Jack W, de Laat J, Hanson K, Soucat A (eds) Incentives and Dynamics in the Ethiopian Health Worker Labour Market. World Bank, Washington, D.C

Hanushek EA, Kain JFA, Rickin FG (2004) Why Public Schools Lose Teachers. J Hum Resour 39(2):326-354

Huber J, Zwerina K (1996) The Importance of Utility Balance in Efficient Choice Designs. J Mark Res 33(3):307-317

Kingdon G, Teal F (2007) Does Performance Related Pay for Teachers Improve Student Achievement? Evidence from India. Econ Educ Rev 26(4):473-486

Kingdon G (2010) The Impact of the Sixth Pay Commission on Teacher Salaries: Assessing Equity and Efficiency Effects. RECOUP Working Paper 29. University of Cambridge, Cambridge

Kolstad JR (2011) How to Make Rural Jobs Attractive to Health Workers. Findings from a Discrete Choice Experiment in Tanzania. Health Econ 20(2):196-211

Kremer M, Muralidharan K, Chaudhury N, Hammer J, Rogers FH (2005) Teacher Absence in India: A Snapshot. J Eur Econ Assoc 3(2-3):658-667

Lagarde M, Blaauw D (2009) A Review of the Application and Contribution of Discrete Choice Experiments to Inform Human Resources Policy Interventions. Hum Resour Heal 7:62

Lancsar E, Louviere J (2006) Deleting 'Irrational' Responses from Discrete Choice Experiments: A Case of Investigating or Imposing Preferences? Health Econ 15(8):797-811

Lusk JL, Norwood FB (2005) Effect of Experimental Design on Choice-based Conjoint Valuation Estimates. Am J Agric Econ 87(3):771-785

Mangham L, Hanson K (2008) Employment Preferences of Public Sector Nurses in Malawi: Results from a Discrete Choice Experiment. Trop Med Int Health 13(12):1433-1441

Mangham L, Hanson K, McPake B (2009) How to do (or not to do) ... Designing a Discrete Choice Experiment for Application in a Low-Income Country. Health Policy Plan 24(2):151-158

McFadden D (1974) Conditional Logit Analysis of Qualitative Choice Behavior. In: Zarembka P (ed) Frontiers in Econometrics. Academic Press, New York, pp 105-142

Metzler J, Woessman L (2010) The Impact of Teacher Subject Knowledge on Student Achievement. Evidence from Within-Teacher Within-Student Variation, IZA Discussion Paper 4999., IZA, Bonn, Germany

Muralidharan K, Sundararaman V (2011) Teacher Performance Pay: Experimental Evidence from India. J Polit Econ 119(1):39-77

Muralidharan K, Sundararaman V (2010) Contract Teachers: Experimental Evidence from India. Unpublished mimeo, University of San Diego, Department of Economics

Penn-Kekana L, Blaauw D, Tint KS, Monareng D, Chege J (2005) Nursing Staff Dynamics and Implications for Maternal Health Provision in Public Health Facilities in the Context of HIV/AIDS. Report for Frontiers in Reproductive Health Program. Population Council, New York

Ramachandran V, Pal M, Jain S, Shekar S, Sharma J (2005) Teacher Motivation in India. Educational Research Unit, India

Ratcliff G, Ganguli M, Chandra V, Sharma S, Belle S, Seaberg E, Pandav R (1998) Effects of Literacy and Education on Measures of Word Fluency. Brain Lang 61(1):115-122

Rawal S, Kingdon G (2010) Akin to My Teacher. Does Caste, Religious and Gender Distance Between Student and Teacher Matter? Some Evidence from India. Some Evidence from India. Department of Quantitative Social Science Working Paper 10-18, Institute of Education, University of London, London

Rosselli M, Ardila A, Salvatierra J, Marquez M, Matos L, Weekes VA (2002) A Cross-Linguistic Comparison of Verbal Fluency Tests. Int J Neurosci 112(6):759-776

Serneels P, Lindelöw M, Garcia-Montalvo J, Barr A (2007) For Public Service or Money Understanding Geographical Imbalances in the Health Workforce. Health Policy Plan 22(3):128-138

Serneels P, Garcia-Montalvo J, Pettersson G, Lievens T, Butera JD, Kidanu A (2010) Who Wants to Work in a Rural Health Post? The Role of Intrinsic Motivation, Rural Background and Faith-Based Institutions in Ethiopia and Rwanda. Bull World Health Organ 88(5):342-349

Sharma R (1999) What Manner of Teacher - Some Lessons from Madhya Pradesh. Econ Pol Wkly 34(25):1597-1607

Street DJ, Burgess L, Louviere JJ (2005) Quick and Easy Choice Sets: Constructing Optimal and Nearly Optimal Stated Choice Experiments. Int J Res Mark 22(4):459-470

Thurstone LL (1938) Primary Mental Abilities. University of Chicago Press, Chicago

WHO (2006) World Health Report 2006: Working Together for Health. World Health Organization, Geneva

doi:10.1186/2193-9020-1-3

Cite this article as: Fagernäs and Pelkonen: Preferences and skills of Indian public sector teachers. IZA Journal of Labor \& Development 2012 1:3. 